\title{
Photosensitization in Porphyrias and Photodynamic Therapy Involves TRPA1 and TRPV1
}

\author{
Alexandru Babes, ${ }^{1,2}$ Susanne K. Sauer, ${ }^{1}$ Lavanya Moparthi, ${ }^{3}$ Tatjana I. Kichko, ${ }^{1}$ Cristian Neacsu, ${ }^{1}$ Barbara Namer, ${ }^{1}$ \\ Milos Filipovic, ${ }^{4}$ Peter M. Zygmunt, ${ }^{5}$ Peter W. Reeh, ${ }^{1}$ and ${ }^{\mathbb{D}}$ Michael J. M. Fischer ${ }^{1}$ \\ ${ }^{1}$ Institute of Physiology and Pathophysiology, Friedrich-Alexander University Erlangen-Nürnberg, 91054 Erlangen, Germany, ${ }^{2}$ Department of Anatomy, \\ Physiology and Biophysics, Faculty of Biology, University of Bucharest, 050095 Bucharest, Romania, ${ }^{3}$ Department of Biochemistry and Structural Biology, \\ Center for Molecular Protein Science, Lund University, SE-221 00 Lund, Sweden, ${ }^{4}$ Department of Chemistry and Pharmacy, Friedrich-Alexander University \\ Erlangen-Nuremberg, 91058 Erlangen, Germany, and ${ }^{5}$ Clinical Chemistry and Pharmacology, Department of Laboratory Medicine, Lund University, SE-221 \\ 85 Lund, Sweden
}

Photosensitization, an exaggerated sensitivity to harmless light, occurs genetically in rare diseases, such as porphyrias, and in photodynamic therapy where short-term toxicity is intended. A common feature is the experience of pain from bright light. In human subjects, skin exposure to $405 \mathrm{~nm}$ light induced moderate pain, which was intensified by pretreatment with aminolevulinic acid. In heterologous expression systems and cultured sensory neurons, exposure to blue light activated TRPA1 and, to a lesser extent, TRPV1 channels in the absence of additional photosensitization. Pretreatment with aminolevulinic acid or with protoporphyrin IX dramatically increased the light sensitivity of both TRPA1 and TRPV1 via generation of reactive oxygen species. Artificial lipid bilayers equipped with purified human TRPA1 showed substantial single-channel activity only in the presence of protoporphyrin IX and blue light. Photosensitivity and photosensitization could be demonstrated in freshly isolated mouse tissues and led to TRP channel-dependent release of proinflammatory neuropeptides upon illumination. With antagonists in clinical development, these findings may help to alleviate pain during photodynamic therapy and also allow for disease modification in porphyria patients.

Key words: aminolaevulinic acid; pain; protoporphyrin IX

Significance Statement

Cutaneous porphyria patients suffer from burning pain upon exposure to sunlight and other patients undergoing photodynamic therapy experience similar pain, which can limit the therapeutic efforts. This study elucidates the underlying molecular transduction mechanism and identifies potential targets of therapy. Ultraviolet and blue light generates singlet oxygen, which oxidizes and activates the ion channels TRPA1 and TRPV1. The disease and the therapeutic options could be reproduced in models ranging from isolated ion channels to human subjects, applying protoporphyrin IX or its precursor aminolevulinic acid. There is an unmet medical need, and our results suggest a therapeutic use of the pertinent antagonists in clinical development.

\section{Introduction}

A key role in the detrimental action of blue to near ultraviolet $\left(\mathrm{UV}_{\mathrm{A}}\right)$ light to human cells is performed by endogenous photo-

\footnotetext{
Received Nov. 26, 2015; revised Feb. 29, 2016; accepted March 22, 2016.

Author contributions: A.B., S.K.S., L.M., B.N., M.F., P.M.Z., P.W.R., and M.J.M.F. designed research; A.B., S.K.S., L.M., T.I.K., C.N., B.N., M.F., and M.J.M.F. performed research; A.B., S.K.S., L.M., T.I.K., C.N., M.F., and M.J.M.F. analyzed data; A.B., P.M.Z., P.W.R., and M.J.M.F. wrote the paper.

A.B. was supported by the Alexander von Humboldt Foundation. C.N., A.B., M.F., and P.W.R. were supported as members of the Emerging Fields Initiative consortium Medicinal Redox Inorganic Chemistry of the University of ErlangenNürnberg. B.N. was supported by DFG Grant NA 970/1-1.P.M.Z. and L.M. were supported by the Swedish Research Council (2014-3801), the Medical Faculty at Lund University, and the Research School of Pharmaceutical Sciences at Lund University. We thank Iwona Izydorczyk, Annette Kuhn, and Susi Haux-Oertel for excellent technical assistance.

The authors declare no competing financial interests.

Correspondence should be addressed to Prof. Dr. med. Peter W. Reeh, Institute of Physiology and Pathophysiology, Universitätsstrasse 17, 91054 Erlangen, Germany. E-mail: peter.reeh@fau.de.
}

sensitizers through photosensitizing reactions of Type I, a direct electron transfer between photosensitizer and substrate, or Type II, an energy transfer to molecular oxygen producing singlet oxygen and reactive oxygen species (ROS). Porphyrins are common photosensitizers. This includes uroporphyrin, coproporphyrin, and protoporphyrin IX (PpIX), which are intermediates in the ubiquitous heme biosynthetic pathway (Wondrak et al., 2006). This pathway is initiated by $\delta$-aminolevulinic acid (ALA)synthase in mitochondria with the production of ALA from glycine and succinyl-CoA. Subsequent chemical reactions catalyzed by various enzymes culminate in the action of ferrochelatase, an 
enzyme that adds ferrous iron to PpIX, resulting in heme formation (Ajioka et al., 2006). Porphyrias are rare diseases caused by loss of function mutations in the genes of enzymes, which participate in the heme biosynthesis pathway. Deficiencies in early steps of the pathway, as for example in acute intermittent porphyria (Herrick and McColl, 2005), lead to accumulation of ALA and/or porphobilinogen and cause neurovisceral symptoms that are not accompanied by cutaneous photosensitivity. However, accumulation of later intermediates, including PpIX, results in severe burning pain ("ice-cold fire on the skin"), itching redness, and eventually blistering and swelling of the skin upon sun or even neon light exposure (Poblete-Gutiérrez et al., 2006; Puy et al., 2010; Balwani and Desnick, 2012). While it is widely accepted that cutaneous photosensitivity in these maladies is due to accumulation of porphyrins in the skin, which enhances the production of free radicals upon exposure to light, the actual molecular mechanism responsible for the pain reported, in particular, by erythropoietic protoporphyria patients within minutes of light exposure (Lecha et al., 2009) has not been investigated in depth.

Exogenously, photosensitization can occur unintentionally by contact with plants that contain photosensitizers (e.g., Berloque dermatitis) (Wang et al., 2002). The vital stain methylene blue can be considered as a model compound as it excites nociceptive nerve terminals in isolated rat skin only when illuminated (Kress et al., 1997). In photodynamic therapy (PDT), photosensitization is induced by excess levels of PpIX, generating singlet oxygen upon illumination, which is used in treating precancerous lesions, nonmelanoma skin cancers, and other skin conditions (Ishizuka et al., 2011). Endoscopic PDT is used to treat neoplasms in the esophagus, bile duct, and bronchi; and in ophthalmology, laser-PDT is used to fight neovascularization in case of "wet" macular degeneration (Muguruma et al., 2012; Nowak-Sliwinska et al., 2013). In general, PDT relies on the administration of photosensitizing drugs that accumulate in tumor cells, followed by illumination with visible light of the appropriate wavelength, leading to generation of ROS and oxidative cell damage. This can be achieved by topical administration of the heme precursor ALA, which is internalized and metabolized to PpIX by target cells, or by systemic medication of PpIX derivatives in nondermatological practice. One of the frequent adverse effects of PDT is pain, which limits the therapeutic use of this approach (Warren et al., 2009; Gholam et al., 2010; Fink et al., 2015). Again, while excess PpIX and ROS generation during illumination is likely to be the underlying cause of pain in PDT, the precise mechanism involved in the activation and sensitization of nociceptors has not been unraveled.

In this study, we focus on TRPA1 and TRPV1, polymodal receptor channels in the pain pathway that are highly expressed in cutaneous nociceptive nerve endings (Caterina et al., 1997; Story et al., 2003). Based on the activation of both TRPA1 and TRPV1 by ROS (Andersson et al., 2008; Chuang and Lin, 2009) and the activation of TRPA1 by exposure to UV light (Hill and Schaefer, 2009), we hypothesized that these channels may mediate the exacerbated pain associated with cutaneous photosensitive porphyrias (particularly erythropoietic porphyria) and PTD. We provide evidence for such a role by investigating the mechanisms underlying photosensitivity and ALA- and PpIX-induced sensitization in heterologous expression systems, cultured primary afferent neurons, and nociceptive nerve endings in intact tissue preparations from wild-type (WT) and null mutant mice, and in a human translational model.

\section{Materials and Methods}

Chemicals and solutions. The standard external solution (ES) used in calcium imaging experiments contained the following (in $\mathrm{mM}$ ): $\mathrm{NaCl}$ $140, \mathrm{KCl} 4, \mathrm{CaCl}_{2} 1.25, \mathrm{MgCl}_{2} 1$, HEPES 10, glucose 5; the $\mathrm{pH}$ was adjusted to 7.4 with $\mathrm{NaOH}$. The extracellular calcium-free solution used in patch-clamp experiments and some calcium imaging experiments contained the following (in $\mathrm{mm}$ ): $\mathrm{NaCl} 140, \mathrm{KCl} 4, \mathrm{MgCl}_{2}$ 2, HEPES 10 , glucose 5; the $\mathrm{pH}$ was adjusted to 7.4 with $\mathrm{NaOH}$. The pipette solution for patch-clamp recordings contained the following (in $\mathrm{mM}$ ): potassium gluconate 135, $\mathrm{MgCl}_{2}$ 3, EGTA 5, $\mathrm{Na}_{2} \mathrm{ATP} 2, \mathrm{Na}_{3} \mathrm{GTP} 0.3, \mathrm{NaCl} 4$, HEPES 5; the $\mathrm{pH}$ was adjusted to 7.25 with $\mathrm{KOH}$. Contents of synthetic interstitial fluid (SIF, in $\mathrm{mM}$ ) used for ex vivo experiments were as follows: $\mathrm{NaCl} 108, \mathrm{KCl} 3.5, \mathrm{MgSO}_{4} 3.5, \mathrm{NaHCO}_{3} 26, \mathrm{NaH}_{2} \mathrm{PO}_{4}$ 1.7, $\mathrm{CaCl}_{2}$ 1.5, sodium gluconate 9.6, glucose 5.5, and sucrose 7.6 (Bretag, 1969). All reagents were purchased from Sigma-Aldrich. PpIX was obtained from Frontier Scientific or Sigma-Aldrich. Fresh stock solutions of ALA (100 mM in external solution), PpIX (10 mM in DMSO), and deferoxamine (DEF, $50 \mathrm{~mm}$ in external solution) were prepared on the day of the experiment. Carvacrol (100 mM, DMSO), allyl isothiocyanate ( $1 \mathrm{~m}$ in ethanol), capsaicin (1 $\mathrm{mm}$ in ethanol), succinyl acetone $\left(10 \mathrm{~mm}\right.$ in $\mathrm{H}_{2} \mathrm{O}$ ), HC-030031 (10 mm in DMSO), and 4-(3-Chloro-2-pyridinyl)-N-[4-(1, 1-dimethylethyl)phenyl]-1-piperazinecarboxamide (BCTC) (10 $\mathrm{mm}$ in ethanol) were kept as stock solution at $-20^{\circ} \mathrm{C}$ and diluted to the working concentration immediately before the experiment. In all experiments, the final concentration of DMSO or ethanol was $\leq 0.1 \%$.

Animals. Breeding and euthanasia and all procedures of animal handling were performed according to regulations of animal care and welfare (TierSchG). Experiments were performed in accordance with the European Communities Council Directive of 24 November 1986 (86/609/ EEC). TRPA1 $1^{-1-}$ mice were donated by Harvard University (Drs. Kelvin Kwan and David Corey, Howard Hughes Medical Institute, Department of Neurobiology, Harvard Medical School, Boston, Massachusetts) and TRPV1 ${ }^{-1-}$ mice by Dr. John Davis (formerly GlaxoSmithKline); both mouse lines were backcrossed onto C57BL/6 for $>15$ generations and used to breed the respective double knock-out mice. Mice of either sex were killed by inhalation of increasing levels of $\mathrm{CO}_{2}$.

Cell culture and transfection. DRGs from all spinal levels were excised from adult male mice and transferred to DMEM containing $50 \mu \mathrm{g} / \mathrm{ml}$ gentamicin. DRGs were treated with $1 \mathrm{mg} / \mathrm{ml}$ collagenase and $0.1 \mathrm{mg} / \mathrm{ml}$ protease for $30 \mathrm{~min}$, mechanically dissociated with a fire-polished silicone-coated Pasteur pipette and plated onto glass coverslips previously coated with poly-D-lysine $(200 \mu \mathrm{g} / \mathrm{ml})$. DRG neurons were cultured in serum-free TNB 100 cell culture medium supplemented with TNB 100 lipid-protein complex and streptomycin/penicillin ( $100 \mu \mathrm{g} / \mathrm{ml}$, all from Biochrom). Mouse NGF was added at $100 \mathrm{ng} / \mathrm{ml}$ (Alomone Labs), and the cells were kept at $37^{\circ} \mathrm{C}$ and $5 \% \mathrm{CO}_{2}$ for up to $24 \mathrm{~h}$.

HEK293t cells were regularly passaged and controlled for mycoplasma contamination. HEK293t cells were transiently transfected with plasmids containing hTRPA1, hTRPV1, and hTRPA1 mutants hTRPA1-C621S/C641S/C665S (hTRPA1-3C) and hTRPA1-C633S/ C651S (hTRPA1-2C) using jetPEI transfection reagent from Polyplus Transfection. The hTRPA1-2C mutant was generated by site-directed mutagenesis (QuikChange II XL, Agilent Technologies). Cells were plated onto poly-D-lysine-coated glass coverslips and used for experiments within $24 \mathrm{~h}$

Calcium and ROS imaging. HEK293t expressing the human isoform of TRPA1 or TRPV1 (hTRPA1, hTRPV1) and DRG neurons plated on glass coverslips were loaded with fura- $2 \mathrm{AM}\left(3 \mu \mathrm{M}, \sim 30 \mathrm{~min}\right.$ at $37^{\circ} \mathrm{C}$, containing also $0.02 \%$ Pluronic, both from Invitrogen) and washed for $\sim 10 \mathrm{~min}$ before recording. Coverslips were then mounted on an Olympus IX71 inverted microscope and imaged using a $10 \times$ objective with 0.4 numerical aperture. Cells were permanently superfused with ES using a software-controlled 7-channel gravity-driven common-outlet system (Dittert et al., 2006). Fura-2 was excited at 340 and $380 \mathrm{~nm}$ with a Polychrome V monochromator (Till Photonics), with a FWHM wavelength range of $\sim 10 \mathrm{~nm}$ (e.g., $380 \mathrm{~nm}$ should be understood as $380 \pm 5 \mathrm{~nm}$ ). Fluorescence emission was long-passed at $495 \mathrm{~nm}$, unless otherwise spec- 
ified, pairs of images were acquired at a rate of $1 \mathrm{~Hz}$ with an exposure time of 4 ms with a 12 bit CCD camera (Imago Sensicam QE, Till Photonics). Data were processed off-line using the TILLvisION 4 (Till Photonics). The background intensity was subtracted before calculating the ratio between the fluorescence emitted when the dye was excited at $340 \mathrm{~nm}$ and at $380 \mathrm{~nm}(\mathrm{~F} 340 / 380 \mathrm{~nm})$. The time course of this ratio was analyzed for regions of interest adapted to individual cells. Response amplitudes were calculated as the integral of the ratio change for a period matching the duration of the stimulus but at least for $30 \mathrm{~s}$. An average increase of the $\mathrm{F} 340 / 380$ ratio $>0.1$ in the analysis period was considered a response. This reflects a calcium increase $>100 \mathrm{~nm}$. To monitor ROS production, HEK293t cells or DRG neurons were incubated with hydroethidine (20 $\mu \mathrm{M}$ in ES, $10 \mathrm{~min}$ ), 123 dihydrorhodamine (DHR, $20 \mu \mathrm{M}$ in ES, $10 \mathrm{~min}$ ) or carboxy-dichlorodihydrofluorescein $\left(\mathrm{H}_{2} \mathrm{DCF}, 25 \mu \mathrm{M}\right.$ in ES, $20 \mathrm{~min}$, all from Invitrogen) and then left for $15 \mathrm{~min}$ to recover, changing the medium every $5 \mathrm{~min}$. These dyes were excited at $480 \mathrm{~nm}$, the emitted fluorescence was recorded using a $510 \mathrm{~nm}$ long pass filter. For light stimulation in addition to fluorescence imaging, cells were exposed to the respective wavelength for $940 / 1000 \mathrm{~ms}$.

Whole-cell patch-clamp recordings. Voltage-clamp experiments were performed on HEK293t cells transiently transfected with a hTRPV1::YFP fusion plasmid or with hTRPA1 equipped with a IRES-based YFP coexpression for selecting successfully transfected cells. Currents were acquired using an Axopatch 200B patch-clamp amplifier (Molecular Devices), low-passed at $1 \mathrm{kHz}$, and sampled at $2 \mathrm{kHz}$; pCLAMP 10 was used for voltage control, data acquisition, and off-line analysis. Patch pipettes were pulled from borosilicate glass tubes (TW150F-3, World Precision Instruments) and heat-polished to a final resistance of 1.7-4.0 $\mathrm{m} \Omega$. Cells were held at $-60 \mathrm{mV}$ and probed every $4 \mathrm{~s}$ by voltage ramps from -100 to $100 \mathrm{mV}$ of $400 \mathrm{~ms}$ duration. Illumination of cells during patch-clamp recordings was performed using a mercury arc lamp and the optical filters of the imaging system (410 nm short pass filter for UV stimulation or a $460-490 \mathrm{~nm}$ bandpass filter).

Single-channel activity in planar lipid bilayers. The expression and purification of hTRPA1 were performed as described previously (Moparthi et al., 2014). Briefly, purified hTRPA1 was reconstituted into preformed planar lipid bilayers composed of 1,2-diphytanoyl-snglycero-3-phosphocholine (Avanti Polar Lipids) and cholesterol (SigmaAldrich) in a 9:1 ratio and produced by using the Vesicle Prep Pro Station (Nanion Technologies). Under these conditions, a uniform protein orientation is favored with $\mathrm{N}$ - and $\mathrm{C}$ termini facing the recording chamber (i.e., the "cytosolic compartment") (Moparthi et al., 2014). PpIX (1 $\mu \mathrm{M})$ was added to this compartment when photosensitization was tested. The $405 \mathrm{~nm}$ laser illumination had a light intensity of $0.45 \mathrm{~mW} / \mathrm{mm}^{2}$ (LT2010, www.miniinthebox.com). This laser wavelength was closest to the observed maximum sensitivity, measured in calcium imaging experiments using the monochromator. Ion channel activity was recorded using the Port-a-Patch (Nanion Technologies) at both positive and negative test potentials in a symmetrical $\mathrm{K}^{+}$solution $(150 \mathrm{~mm} \mathrm{KCl}, 10$ mM HEPES) adjusted to pH 7.2 with KOH. Signals were acquired with an EPC 10 amplifier and PatchMaster software (HEKA) at a sampling rate of $50 \mathrm{kHz}$. The patch-clamp experiments were performed at room temperature. Electrophysiological data were analyzed using Clampfit 9 (Molecular Devices) and Igor Pro (WaveMetrics). Data were processed by a Gaussian low-pass filter at 1000 for analysis and 100 or $500 \mathrm{~Hz}$ for traces. The single-channel mean conductance $\left(G_{s}\right)$ was obtained from Gaussian fit of all-points amplitude histograms. The single-channel mean open probability $\left(\mathrm{P}_{\mathrm{o}}\right)$ was calculated from time constant values, which were obtained from exponential standard fits of dwell time histograms.

Calibration of cellular light stimulation. The intensity of the light beam in the inverted microscope was calibrated using a $468 \mathrm{~nm}$ light emitting diode (LED) with a peak emission of $650 \mathrm{mcd}$ over a solid angle of 0.076 steradian (and therefore a luminous flux of 0.05 lumen). The luminous flux of the LED was converted using the luminosity function to a power of $0.87 \mathrm{~mW}$. The LED and the monochromator light intensities were measured with a S2386 photodiode (Hamamatsu Photonics), and the measurements were corrected for wavelength-dependent sensitivity. The Polychrome V monochromator (see above) illuminated an area of 6 $\mathrm{mm}^{2}$ in a largely homogeneous fashion and had an almost constant power output of $0.4 \mathrm{~mW} / \mathrm{mm}^{2}$ in the range $360-400 \mathrm{~nm}$. This translates to $0.0076 \mathrm{~mW} / \mathrm{mm}^{2}$ when only fluorescence at 340 and $380 \mathrm{~nm}$ was measured once per second for calcium measurement and $\sim 0.36 \mathrm{~mW} /$ $\mathrm{mm}^{2}$ for light stimulation $(940 / 1000 \mathrm{~ms})$ in addition to fluorescence imaging.

Neuropeptide release. The experiments measuring release of CGRP were performed as previously described (Averbeck and Reeh, 2001; Kichko et al., 2015). Briefly, hindpaw skin flaps of adult mice were carefully excised and washed for $30 \mathrm{~min}$ in carbogen-saturated synthetic interstitial fluid with or without PpIX $(5 \mu \mathrm{M})$. Experiments in a $25^{\circ} \mathrm{C}$ water bath consisted of three $10 \mathrm{~min}$ incubation steps in glass tubes filled with $700 \mu \mathrm{l}$ SIF. In the second step, the preparations were continuously illuminated through a triple light guide by a standard cold light source (150 W, KL1500, Schott) immersed in the bath. Thermal effects of the light source were determined by a thermocouple to $\leq 0.2^{\circ} \mathrm{C}$ increase. The mouse trachea was excised together with the two main bronchi, cut open along the dorsal midline, and mounted upside down on a triangular aluminum block $\left(22^{\circ} \mathrm{C}\right)$ for continuous gravity-driven superfusion in the natural direction of the mucus flow. Light stimulation was performed for a period of $5 \mathrm{~min}$ using a $405 \mathrm{~nm}$ laser, defocused to provide a homogeneous rectangular illuminated area of $15 \times 10 \mathrm{~mm}$ from a distance of 130 $\mathrm{mm}$. The respective light intensity measured with a calibrated power meter at this distance was $0.45 \mathrm{~mW} / \mathrm{mm}^{2}$ (VEGA with 3A-ROHS sensor, Ophir Photonics). During light stimulation, the surface temperature of the trachea rose from $22 \pm 0.5^{\circ} \mathrm{C}$ to $23 \pm 0.6^{\circ} \mathrm{C}$ as determined by a clinical infrared thermometer (FTN, Medisana). The CGRP content of the incubation fluid was measured using a commercial enzyme immunoassay kit (Bertin Pharma) as previously described (Averbeck and Reeh, 2001). The enzyme immunoassay plates were analyzed photometrically using a microplate reader (Dynatech).

Human psychophysical experiments. Human experiments have been conducted according to the Declaration of Helsinki. The experiments and the subject's consent forms were approved by the institutional Ethics Committee of the University of Erlangen. Seven healthy volunteers (aged 39-66 years, 2 female), educated about the purpose of the study, signed the informed consent form at least one day before the experiments and completed a medical history questionnaire. On the day of the experiments, subjects were seated comfortably in a dentistry chair and injected with $100 \mu \mathrm{l}$ of sterile SIF or ALA $(1,3.1$, and $10 \mathrm{~mm})$ diluted in SIF in a double-blinded design. Solutions were randomized and blinded by an independent person not involved in the experiment and only unblinded after the experiment. Injection sites were covered to avoid light exposure. Three hours after injection into the volar side of the forearm, light stimulation was first tested at untreated skin as training, and then the four test sites were stimulated at an interval of $5 \mathrm{~min}$. For light stimulation, the defocused $405 \mathrm{~nm}$ laser mentioned above was positioned directly on the skin with a 5 -mm-thick rubber foam spacer, generating a rectangular light spot of $6 \times 4 \mathrm{~mm}$ with an intensity of $3.2 \mathrm{~mW} / \mathrm{mm}^{2}$ at the skin surface. The pain intensity was reported by the subjects every $5 \mathrm{~s}$ by means of a numeric rating scale (NRS, $0-100$ ) with the fixed points "no sensation" (0), "minimal pain" (10), and "maximum imaginable pain" (100). Stimulation was terminated after $60 \mathrm{~s}$ or when reaching a rating of 50. Subjects were instructed to indicate the rating of 50 at any time; the exact time was then recorded. For averaging, a value of 50 was assumed for all time points after termination before $60 \mathrm{~s}$. Subjects were instructed to avoid light exposure within $48 \mathrm{~h}$ of the injection.

Statistics. Data are presented as mean \pm SEM. Two experimental groups were compared by $t$ tests for dependent or independent samples. Multiple groups were evaluated by ANOVA followed by a HSD post hoc test. Analysis was performed using Statistica 7 (StatSoft). All statistical tests were two-sided. A value of $p<0.05$ was considered statistically significant and is reported with three valid digits.

Study approval. Animal experiments were approved by the Animal Authority of the District Government of Mittelfranken (Ansbach, Germany). Human studies were approved by the University's Ethics committee (375-14 B). 

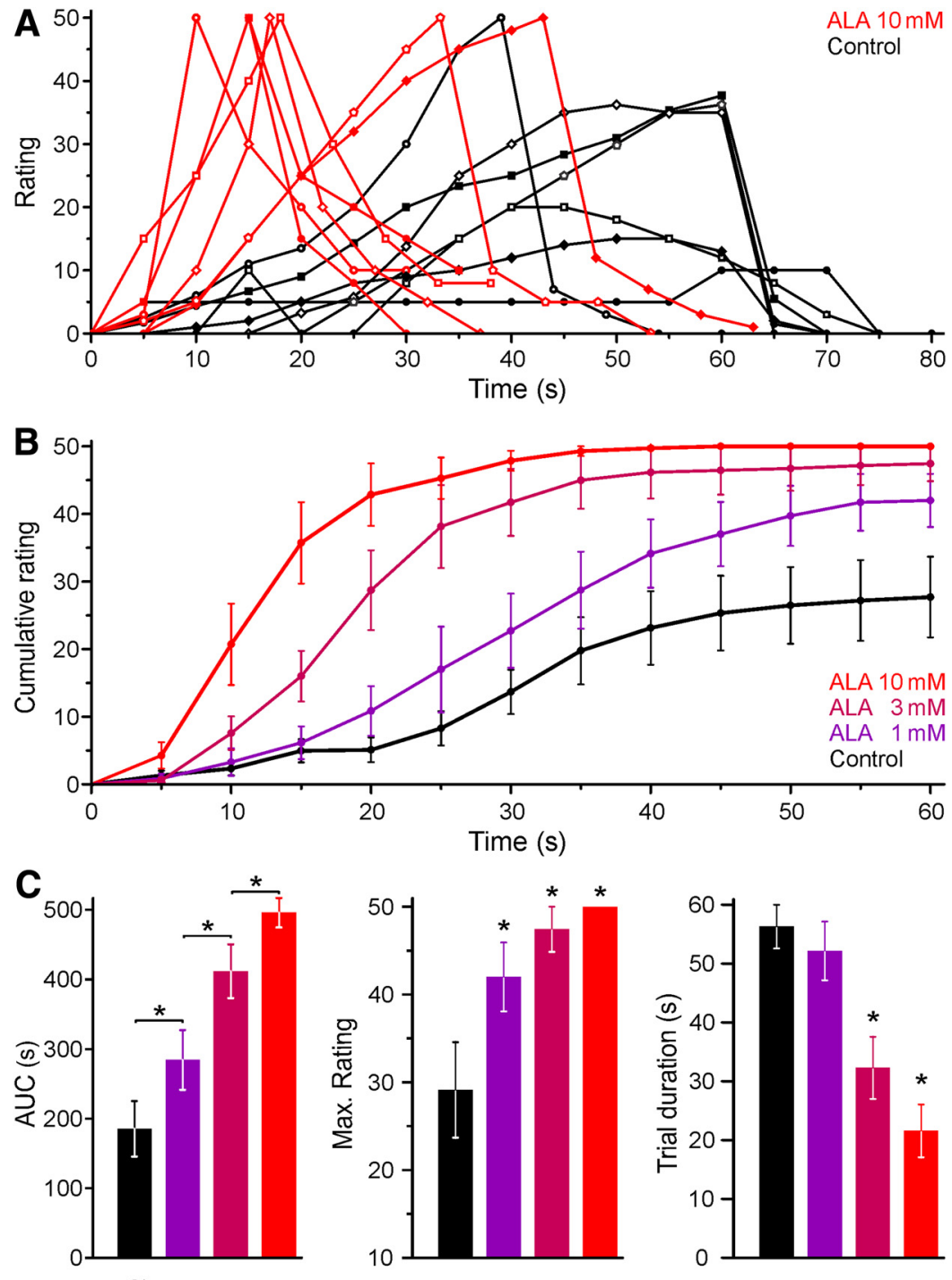

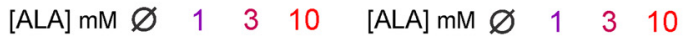

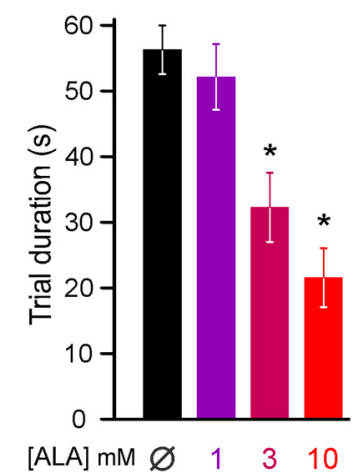

Figure 1. ALA sensitizes human skin to blue light illumination. In healthy human volunteers, ALA was injected into the epidermal layer of the skin. After a period of $3 \mathrm{~h}$, the skin was illuminated with a $405 \mathrm{~nm}$ laser. Subjects rated the painful sensation on a numerical scale (1-100) every $5 \mathrm{~s}$; the illumination was terminated after $60 \mathrm{~s}$ or when reaching a rating of 50 . $\boldsymbol{A}$, Time course of individual pain ratings induced by blue light after ALA $10 \mathrm{~mm}$ or control solution. The trials of the same subject are indicated by the same symbol. Recovery was recorded for $20 \mathrm{~s}$ after the end of the light stimulation. $\boldsymbol{B}$, The averaged pain rating of 7 volunteers shows a concentration-dependent increase in the pain rating after ALA compared with control. For trials terminated earlier, a rating of 50 was extrapolated for all subsequent time points. C, ALA pretreatment photosensitized, which manifests as an increased area under the curve (AUC) of the rating, an increased maximum rating reported in a trial, and a decreased trial duration. ${ }^{*} p<0.05$.

\section{Results}

\section{ALA enhances the pain produced by $405 \mathrm{~nm}$ stimulation in} human subjects

PDT with ALA is known to cause photosensitization and burning pain during therapeutic irradiation with red light used for the sake of deeper skin penetration. We asked whether the illumination of the skin with a violet laser, providing the optimal wavelength $(405 \mathrm{~nm})$ to excite endogenous PpIX, would also evoke pain in the absence of photosensitization. Accounting for the minor penetration depth of violet as opposed to red light and the keratinized epidermis, the laser was adjusted to deliver $3.2 \mathrm{~mW} /$ $\mathrm{mm}^{2}$ at the skin surface. In pilot experiments, this stimulus applied to the un-tanned volar forearm caused pin-prick sensations within $\sim 30$ s that developed into moderate burning pain at $\sim 60$ s and could easily be tolerated for another minute; the temperature of the skin rose by $2.2 \pm 0.3^{\circ} \mathrm{C}(n=7)$ in these 2 min. Based on this experience, 7 healthy volunteers were recruited and doubleblind experiments performed with intradermal injections $(100 \mu \mathrm{l})$ of various ALA concentrations $(1,3$, and $10 \mathrm{~mm})$ and vehicle. After an uneventful period of $3 \mathrm{~h}$ following injections, the $405 \mathrm{~nm}$ illumination revealed a painful concentrationdependent photosensitization. This is apparent in the individual trials (Fig. $1 A)$ and in the average reported pain rating (Fig. $1 B$ ). The area under the curve and the maximum pain rating increased in a concentration-dependent manner (ANOVA, planned comparisons for the area under the curve of adjacent concentrations and HSD-post hoc tests compared with control). The cutoff was reached earlier at higher ALA concentrations, which decreased the average trial duration versus control for ALA $3 \mathrm{~mm}$ and above (HSDpost hoc tests, $p<0.05$, Fig. $1 C$ ). It should be noted that injections of ALA could not be distinguished from vehicle and did not cause any pain in the $3 \mathrm{~h}$ interval between injection and illumination, during which the injected skin was protected from ambient light. Having demonstrated that blue light irradiation itself causes pain, which is strongly enhanced following treatment with ALA, our aim was to identify the molecular targets responsible for this photoactivation and photosensitization of nociceptors.

\section{Activation of TRPA1 by near UV light is mediated by formation of ROS}

Human TRPA1 and TRPV1 were transiently expressed in HEK293t cells and exposed to $U_{\mathrm{A}}$ light $(390 \mathrm{~nm}, 85 \mathrm{~s}$ exposure in $90 \mathrm{~s})$. Cells expressing hTRPA1 displayed large calcium transients in response to this light stimulus, compared with minimal responses in hTRPV1expressing cells and no responses in untransfected HEK293t cells (Fig. 2A). To obtain the action spectrum of light-dependent activation of hTRPA1, cells were stimulated by monochromatic light in the range of 360-470 $\mathrm{nm}$ for $2 \mathrm{~min}$ in separate experiments. Activation of hTRPA1 occurred in a wide wavelength range, but with a clear optimum in the range of 410-430 nm (Fig. 2B). Using the other optical cubes of the microscope, no activation was observed by $2 \mathrm{~min}$ of stimulation at 488 or $562 \mathrm{~nm}$.

The source of the constitutive light-evoked calcium transients in hTRPA1-expressing cells was investigated. In the absence of extracellular calcium ions, exposing the cells to $390 \mathrm{~nm}$ failed to evoke an increase in intracellular calcium concentration $\left(\left[\mathrm{Ca}^{2+}\right]_{\mathrm{i}}\right)$, demonstrating a stimulated calcium entry by $\mathrm{UV}_{\mathrm{A}}$ light (Fig. 2C). The involvement of TRPA1 in the generation of these calcium transients was tested using the selective TRPA1 
antagonist HC-030031 (10 $\mu \mathrm{M})$, which completely abolished the response to 390 $\mathrm{nm}$ (Fig. 2D). Interestingly, upon return to a calcium-containing external solution (Fig. 2C), or upon removal of the antagonist (Fig. 2D), large rebound calcium transients were generated even in the absence of illumination, suggesting either the accumulation of an intracellular chemical agonist produced by $390 \mathrm{~nm}$ light, or an outlasting modification of TRPA1, which are both able to trigger calcium entry once it becomes available or the antagonist is removed. Activation of TRPA1 by electrophilic compounds involves certain critical cysteine residues located in the cytoplasmic N-terminal domain of the protein (Macpherson et al., 2007). The role of these residues in the activation of hTRPA1 by $\mathrm{UV}_{\mathrm{A}}$ light was investigated in two mutants: hTRPA1-3C, in which cysteines were substituted by serines in positions 621,641 , and 665 ; and hTRPA1-2C, in which the cysteines C633 and $\mathrm{C} 651$ involved in disulfide bonds with the cysteines of the hTRPA1-3C mutant were replaced by serine (Eberhardt et al., 2012, 2014). Cells transfected with either mutant displayed substantially diminished responses to $\mathrm{UV}_{\mathrm{A}}$ light: the response of the hTRPA1-3C mutant to $390 \mathrm{~nm}$ (90 s) was reduced by $\sim 70 \%$ (Fig. $2 E$ ), the response of the hTRPA1-2C mutant to the same stimulus was completely abolished (Fig. $2 F)$; both mutants were well activated by carvacrol.

The activation of hTRPA1 by $390 \mathrm{~nm}$ light was antagonized by the antioxidants NAC and dithiothreitol (DTT) acting as ROS scavengers. Compared with the light-induced rise of $\left[\mathrm{Ca}^{2+}\right]_{i}$ of hTRPA1expressing cells in control experiments, the response was substantially reduced after pretreatment with either NAC $(10 \mathrm{~mm}$, $4 \mathrm{~h}, 55 \%$ decrease, $t$-test independent samples, $p<0.001, n=178$ for control and 129 for NAC-treated cells; Fig. $2 G$ ) or DTT ( $5 \mathrm{~mm}, 4 \mathrm{~h}, 67 \%$ decrease, $p<0.001$, $n=77$ for control and 110 for DTTtreated cells; Fig. $2 H$ ). This suggests that oxidative processes, likely the formation of disulfides between cysteine thiols, are involved in the activation of TRPAl at $390 \mathrm{~nm}$

Transfected cells were also exposed to UV light using the $30 \mathrm{~W}$ mercury lamp of the inverted microscope and a $410 \mathrm{~nm}$ short-pass filter. In whole-cell voltageclamp mode and calcium-free conditions, UV stimulation caused membrane currents in hTRPA1expressing cells (Fig. 3A) but not in untransfected HEK293t cells. Voltage ramps induced slightly outwardly rectifying currents with a reversal potential close to $0 \mathrm{mV}$ (Fig. 3B). UV illumination
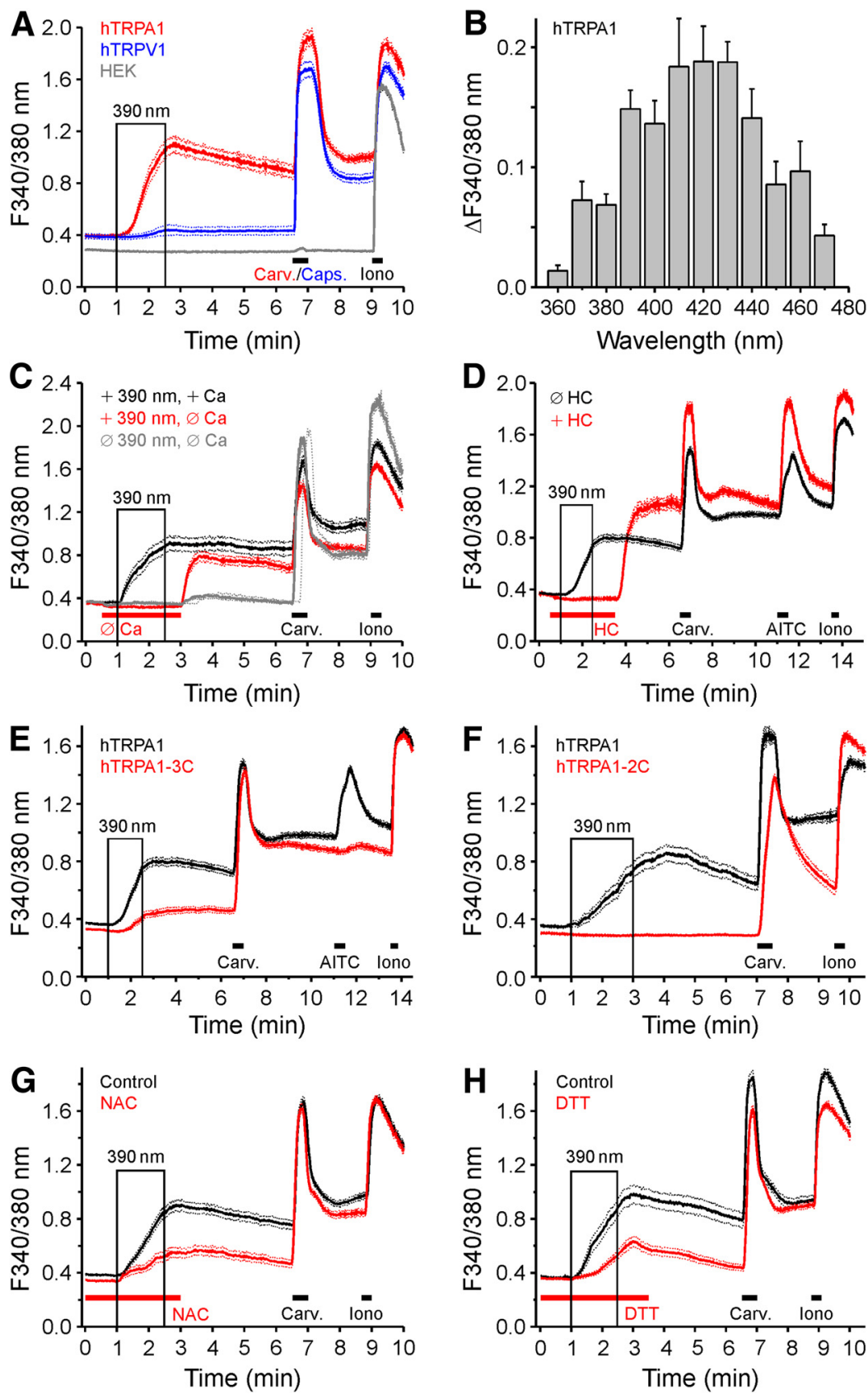

Figure 2. Characterization of UV-induced activation of hTRPA1 and hTRPV1. $\boldsymbol{A}$, UV light ( $390 \mathrm{~nm}, 85$ s illumination within $90 \mathrm{~s})$ evokes calcium transients in hTRPA1-expressing HEK293t cells $(n=108)$ and, to a lesser extent, in cells expressing hTRPV1 ( $n=$ $170)$, but does not activate untransfected cells $(n=91)$. Carvacrol (Carv., $100 \mu \mathrm{m})$ and capsaicin (Caps., $300 \mathrm{~nm})$ were used to confirm functional expression of hTRPA1 and hTRPV1. $\boldsymbol{B}$, The action spectrum of hTRPA1 activation was tested using monochromatic light stimulation for $120 \mathrm{~s}$ at the given wavelength $\pm 5 \mathrm{~nm}$. C, Compared with control conditions $(n=92)$, light-induced activation was absent without extracellular calcium, but large calcium transients were observed when calcium was resupplied $(n=97)$. In the absence of UV stimulation, the rebound calcium transient was substantially smaller $(n=83)$. D, hTRPA1expressing cells were stimulated with $390 \mathrm{~nm}$ in the absence $(n=289)$ and in the presence $(n=103)$ of the TRPA1 antagonist HC-030031 (10 $\mu \mathrm{M} \mathrm{HC).} \boldsymbol{E}, \boldsymbol{F}$, The UV-induced activation of TRPA1 depends on critical N-terminal cysteines. Compared with WT hTRPA1 ( $n=289$ and $n=71$ ), the hTRPA1-3C mutant (hTRPA1-C621S/C641S/C665S; $n=222$ ) and the hTRPA1-2C mutant (hTRPA1-C633S/C651S, $n=54$ ) showed a reduced response UV. $\mathbf{G}, \boldsymbol{H}$, The UV-induced activation of TRPA1 is mediated by R0S production. HEK293-hTRPA1 were illuminated with UV light in control conditions ( $n=178$ and $n=77$ ), or upon pretreatment with NAC (10 mm, $4 \mathrm{~h} ; \boldsymbol{G}, n=129)$ or DTT ( $5 \mathrm{~mm}, 4 \mathrm{~h} ; \boldsymbol{H}, n=110)$. Both NAC and DTT reduced the UV response amplitude, whereas the carvacrol response is unaffected. Data are mean \pm SEM.

for $>30$ s frequently resulted in seal destabilization. The TRPA1 agonist carvacrol $(100 \mu \mathrm{M})$ caused similar but stronger currents, and the UV-evoked membrane currents were completely inhibited by the TRPA1 antagonist HC-030031 (10 $\mu \mathrm{M})$. The same UV 

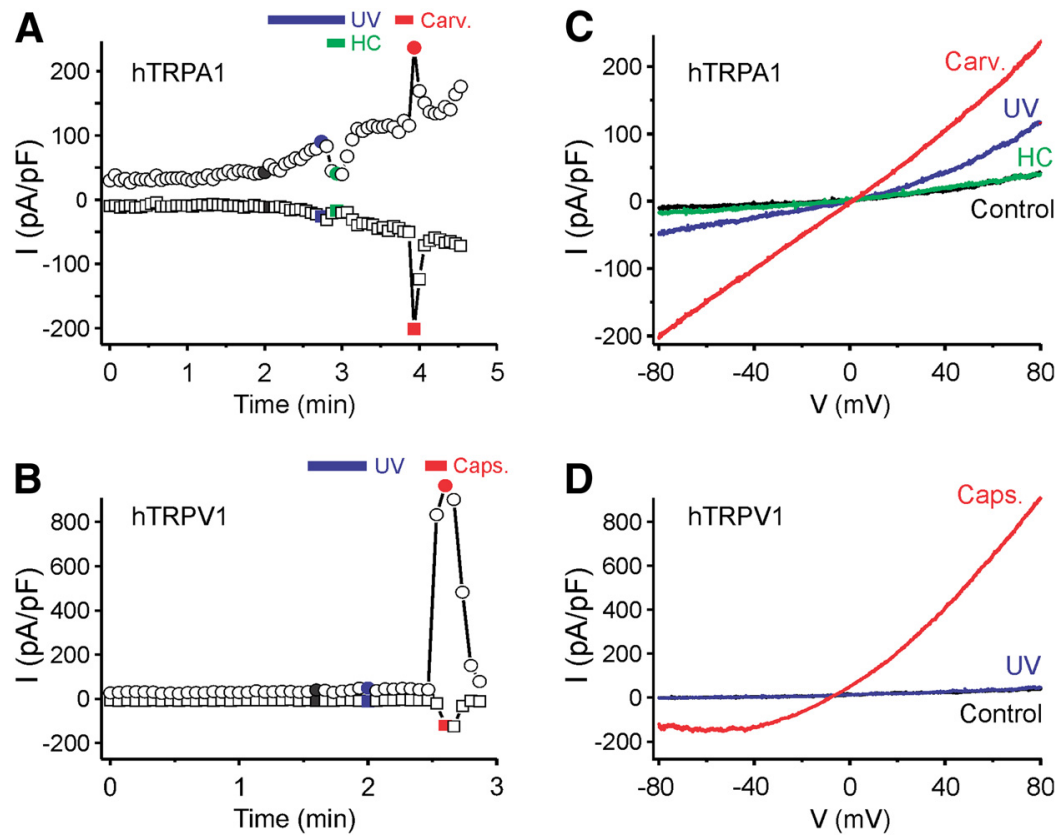

Figure 3. Exposure to UV light induces membrane currents in hTRPA1- but not in hTRPV1-expressing cells. $\boldsymbol{A}$, Example of a whole-cell patch-clamp recording from a hTRPA1-expressing HEK293t cell stimulated by UV light $(<410 \mathrm{~nm})$ and carvacrol (Carv., $100 \mu \mathrm{m})$. Following UV stimulation, the TRPA1 antagonist HC-030031 (HC, $10 \mu \mathrm{m}$ ) was applied, leading to a complete inhibition of the current. $\boldsymbol{B}$, Example of a whole-cell patch-clamp recording from a hTRPV1-expressing HEK293t cell stimulated by UV light (blue bar) and capsaicin (Caps., $1 \mu \mathrm{M}$ ). Illumination with UV light for $30 \mathrm{~s}$ did not evoke a TRPV1-mediated current in this cell. $\boldsymbol{A}, \boldsymbol{B}$, Plot of currents at $-80 \mathrm{mV}$ (squares) and $80 \mathrm{mV}$ (circles) extracted from voltage ramps. $\boldsymbol{C}, \boldsymbol{D}$, Ramp currents recorded at the times indicated with the corresponding color in $\boldsymbol{A}$ and $\boldsymbol{B}$.

stimulus failed to elicit membrane currents in hTRPV1-expressing cells, in agreement with the low level of light-induced activity observed in calcium imaging experiments (Fig. 3C,D).

In DRG neurons from TRPA1 ${ }^{-/-}$mice, $390 \mathrm{~nm}$-illumination induced approximately one-third of the calcium increase observed in C57BL/ 6 neurons $(p<0.001, n=194$ for C57BL/ 6 and $n=158$ for TRPA1 $1^{-/-}$; Fig. $4 A$ ). In the 194 C57BL/6 DRG neurons, $41(21 \%)$ responded to light exposure with an increase in $\left[\mathrm{Ca}^{2+}\right]_{\mathrm{i}}$. Of these 41 neurons, $34(83 \%)$ were also activated by carvacrol. Only 7 of $116(6 \%)$ carvacrol-insensitive neurons were activated by the $390 \mathrm{~nm}$ stimulus. This indicates a strong coexpression of the sensitivities to light and carvacrol in cultured DRG neurons from C57BL/6 mice (Fig. 4B). Carvacrol (100 $\mu \mathrm{M}$ ) activated $40 \%$ and capsaicin $(1 \mu \mathrm{M}) 61 \%$ of all DRG neurons tested. In contrast, in TRPA $1^{-/-}$mice, the sensitivity to both UV light and carvacrol was almost completely abolished. Only 1 of the 158 neurons from TRPA1 $1^{-/-}$DRGs responded to the $390 \mathrm{~nm}$ stimulus, and only 7 neurons (4\%) were activated by carvacrol, whereas 92 (58\%) were activated by capsaicin (Fig. 4B). These results demonstrate that the neuronal responsiveness to illumination at $390 \mathrm{~nm}$ is primarily mediated by TRPA1.

Short wavelength light is able to generate ROS, including singlet oxygen, superoxide anion radical, and hydrogen peroxide, in the presence of endogenous photosensitizers, such as the ubiquitous PpIX. To investigate whether the activation of TRPA1 by $\mathrm{UV}_{\mathrm{A}}$ light occurs via ROS, we monitored the production of cellular ROS by $390 \mathrm{~nm}$ illumination in hTRPA1-expressing cells and DRG neurons. For this purpose, the cells were loaded with the fluorescent ROS indicators hydroethidine, dihydrorhodamine 123, and dichlorodihydrofluorescein diacetate. While dihydrorhodamine 123 yielded no response in either cell type, hydroethidine and in particular dichlorodihydrofluorescein diacetate displayed large increases in fluorescence upon exposure of both HEK293t cells (Fig. 4C) and DRG neurons (Fig. 4D) to the same $\mathrm{UV}_{\mathrm{A}}$ stimulus as used for hTRPA1 activation, indicating that substantial production of ROS occurs as a result of illumination.

\section{ALA induces photosensitization of cells expressing TRPA1 and TRPV1}

ALA is a precursor in the biochemical pathway leading to heme formation (Ajioka et al., 2006) and is used in PDT for the treatment of a variety of skin conditions (Warren et al., 2009). We investigated photosensitivity of TRPA1- and TRPV1-expressing HEK293t cells after prolonged pretreatment with ALA. Cells were incubated in the dark with ALA (0.2-1 mM, 30-240 min in DMEM), after which the medium was removed and cells were loaded with fura-2 for $30 \mathrm{~min}$ and washed for 10 min before calcium microfluorimetry. After this treatment, the brief alternating illumination at 340 and 380 $\mathrm{nm}$ ( $1 \mathrm{~Hz}, 10 \mathrm{~ms}$ each) used to excite fura-2 during calcium imaging was sufficient to evoke an increase in $\left[\mathrm{Ca}^{2+}\right]_{i}$ in HEK293t cells expressing hTRPA1, and, to a lesser extent, also in cells expressing hTRPV1 (Fig. $5 A, B$ ), but not in untransfected HEK293t cells. This light-induced increase in $\left[\mathrm{Ca}^{2+}\right]_{\mathrm{i}}$ required extracellular calcium in both hTRPA1- and hTRPV1expressing HEK293t cells (Fig. 5C,D) and was abolished by the application of selective antagonists HC-030031(10 $\mu \mathrm{M}$, Fig. $5 E)$ and BCTC ( $1 \mu \mathrm{M}$, Fig. $5 F)$.

Light-evoked membrane currents were recorded by wholecell patch clamp in the voltage-clamp mode after pretreatment of TRPA1- and TRPV1-expressing cells with ALA (300 $\mu \mathrm{M}, 3 \mathrm{~h})$. The cells were submitted to $400 \mathrm{~ms}$ voltage ramps from -100 to $100 \mathrm{mV}$ every $4 \mathrm{~s}$ and were illuminated by a mercury lamp and a 460-490 nm bandpass filter for blue light stimulation. Although illumination with blue light for $1 \mathrm{~min}$ did not induce any change in the currents recorded in untreated cells (both $n=5$ cells expressing hTRPA1 or hTRPV1), after pretreatment with ALA the same stimulus generated obvious membrane currents in cells expressing hTRPA1 or hTRPV1 (both $n=5$; Fig. $5 G, H$ ). These currents were outwardly rectifying, had a reversal potential close to $0 \mathrm{mV}$, and were inhibited by application of the respective antagonists HC-030031 and BCTC (Fig. 5G-J).

Exogenous ALA enters the heme biosynthesis pathway and is converted to porphobilinogen by the enzyme ALA-dehydratase. To demonstrate the involvement of this pathway, we investigated whether succinyl acetone, an inhibitor of ALA-dehydratase (Gibson et al., 2001), can prevent the ALA-induced photosensitization. Succinyl acetone $(1 \mu \mathrm{M}, 4 \mathrm{~h})$ alone did not alter the response of hTRPA1-expressing HEK293t cells to the brief UV pulses for fura-2 excitation. However, cells pretreated with succinyl acetone $(1 \mu \mathrm{M}, 1 \mathrm{~h})$ and then exposed to ALA $(300 \mu \mathrm{M})$ and succinyl acetone $(3 \mathrm{~h})$ displayed substantially reduced photosensitivity compared with cells exposed to ALA only (Fig. 6A). This indicates that a reduced conversion of ALA decreases photosensitization. The final step in the heme pathway is the enzymatic conversion of 
PpIX to heme through the insertion of ferrous iron, occurring in the mitochondria. The responsible enzyme, ferrochelatase, can be inhibited by iron-chelating agents, such as DEF (Fukuhara et al., 2013). We hypothesized that inhibiting ferrochelatase, thus mimicking erythropoetic porphyria, would increase photosensitivity due to an accumulation of the endogenous photosensitizer PpIX. This was confirmed by exposing hTRPA1-expressing HEK293t cells to DEF (500 $\mu \mathrm{M})$, which resulted in a exposure-dependent augmentation of the response to the brief UV pulses used to excite fura- 2 and to an additive effect to ALA (200 $\mu \mathrm{M}$; Fig. $6 B-D$ ). Together, these results confirm that exogenous ALA leads to increased photosensitivity in hTRPA1-expressing cells by enhancing PpIX production.

DRG neurons pretreated with ALA $(600 \mu \mathrm{M}, 3 \mathrm{~h})$ and loaded with fura- 2 were illuminated by 340 and $380 \mathrm{~nm}(10 \mathrm{~ms}$ each, sampling rate $1 \mathrm{~Hz}$ ). This illumination activated 30\% (93 of 310) of WT neurons; substantially fewer responses occurred in both TRPA $1^{-1-}$ (18\%, 53 of 297; $p<0.001, \chi^{2}$ test) and TRPV $1^{-1-}$ mice $(19 \%, 56$ of $295 ; p=0.002$; Fig. $6 E)$. The average amplitude of the increase in $\left[\mathrm{Ca}^{2+}\right]_{\mathrm{i}}$ induced in DRG neurons by $340 /$ $380 \mathrm{~nm}$ illumination was reduced after genetic ablation of either TRPA1 (to 33\%, $p<0.001, t$ test independent samples) or TRPV1 (to 46\%, $p<0.001$ ). In DRG neurons cultured from WT mice, light sensitivity was strongly correlated with the responsiveness to carvacrol and capsaicin: $61 \%$ of light-sensitive neurons responded to carvacrol and $83 \%$ to capsaicin; $>90 \%$ of light-sensitive neurons were activated by either carvacrol or capsaicin or both. Moreover, of WT DRG neurons that responded to carvacrol, capsaicin, or both, $48 \%$ (84 of 174) were also activated by UV light. In contrast, only 7\% (9 of 136) of carvacrol-insensitive and capsaicin-insensitive neurons were activated by UV light. In TRPV1 $1^{-1-}$ DRGs, $84 \%$ of photosensitive neurons also responded to carvacrol; and in TRPA1 $1^{-/-}, 81 \%$ of photosensitive neurons also responded to capsaicin (Fig. $6 F)$. The ALA-induced light sensitivity was dependent on TRPA1 and TRPV1, as it was almost entirely abolished in DRGs from TRPA $1^{-/-} / T R P V 1^{-/-}$mice (only 3 of 399 neurons were light-activated).

\section{PpIX-induced photosensitization is mediated by TRPA1 and TRPV1}

Exposure to exogenous ALA leads to accumulation of the photosensitizer PpIX through the heme pathway within the cells. We investigated whether PpIX is able to photosensitize cells expressing recombinant hTRPA1 and hTRPV1 by acutely exposing the cells to PpIX. In the presence of PpIX, the brief UV pulses used to excite fura-2 induced a concentration-dependent rise in $\left[\mathrm{Ca}^{2+}\right]_{\mathrm{i}}$ in both hTRPA1- and hTRPV1-expressing HEK293t cells, whereby higher PpIX concentration increased the slope of the calcium rise rather than the finally reached $\left[\mathrm{Ca}^{2+}\right]_{\mathrm{i}}$ (Fig. $\left.7 A, B\right)$. PpIX was highly potent; therefore, the concentrations were further reduced

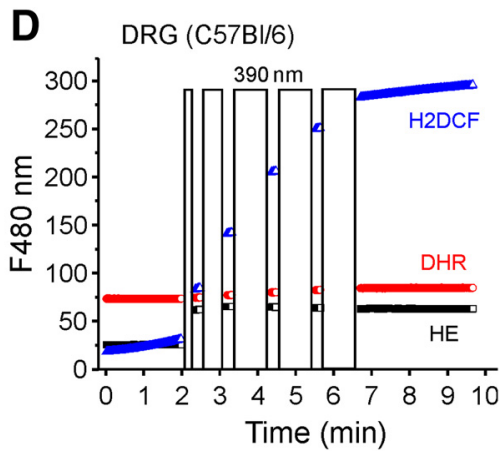

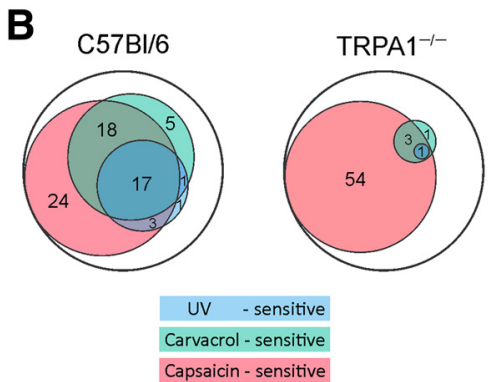

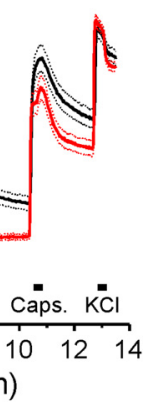

$\begin{array}{cc}6 & 8 \\ \text { Time }(\mathrm{min})\end{array}$
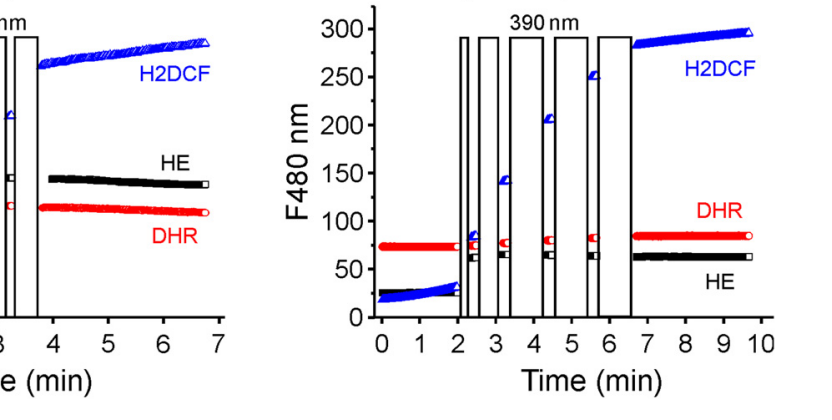

Figure 4. UV illumination generates ROS and is almost exclusively mediated by TRPA1 in DRG neurons. $A$, Neuronal responses , Venn diagram of WT and TRPA1 ${ }^{-1-}$ DRG neuron populations in percentage that responded to UV light ( $390 \mathrm{~nm}, 4 \mathrm{~min}$ ), for HEK293-hTRPA1 and DRG neurons). Note the substantial increase in HE and $\mathrm{H}_{2}$ DCF fluorescence but not DHR fluorescence upon UV illumination in both hTRPA1-expressing cells and DRG neurons.

to 0.1 and $1.0 \mathrm{nm;} \mathrm{PpIX} \mathrm{was} \mathrm{first} \mathrm{applied} \mathrm{in} \mathrm{the} \mathrm{dark,} \mathrm{then} \mathrm{in} \mathrm{the}$ presence of the $340 / 380 \mathrm{~nm}$ fura-2 excitation and finally during continuous illumination with $360 \mathrm{~nm}$ UV light, each for $1 \mathrm{~min}$. In hTRPA1-expressing cells, $1 \mathrm{~nm}$ PpIX caused a small calcium increase in the dark. At both 0.1 and $1 \mathrm{nM}$, PpIX acted as a concentration-dependent photosensitizer enhancing hTRPA1 activation by $360 \mathrm{~nm}$ light (Fig. 7C). A similar photosensitization to $360 \mathrm{~nm}$ light was recorded in hTRPV1-expressing cells (Fig. 7D). Specific involvement of hTRPA1 in the photosensitizing action of PpIX was demonstrated by complete inhibition for as long as HC-030031 (10 $\mu \mathrm{M})$ was present (Fig. $7 E)$. To investigate whether intracellular PpIX is sufficient to photosensitize cells expressing hTRPA1, we only pretreated the cells for $10 \mathrm{~min}$ with PpIX $(10-1000 \mathrm{~nm})$, relying on the fact that the compound is lipophilic and membrane-permeable. The subsequent 340/ $380 \mathrm{~nm}$ fura-2 excitation in the absence of extracellular PpIX resulted in concentration-dependent light-evoked calcium transients (Fig. $7 F$ ). However, only the highest PpIX concentration tested $(1 \mu \mathrm{M})$ reached the effect magnitude of the coapplication of PpIX with the UV light stimuli. This suggests that also extracellular PpIX, generating membrane-permeable singlet oxygen upon illumination, may contribute to hTRPA1 activation by oxidation (Snyder et al., 2005).

To scrutinize PpIX-induced photosensitization, whole-cell membrane currents were recorded. Application of PpIX (20 nM, 2 $\mathrm{min}$ ) in the dark did not produce any change in membrane currents in HEK293t cells expressing hTRPA1 or hTRPV1 cells (both $n=5$ ). Similarly, without PpIX applications, illumination with blue light (460-490 $\mathrm{nm}$ bandpass filter) did not elicit any change 

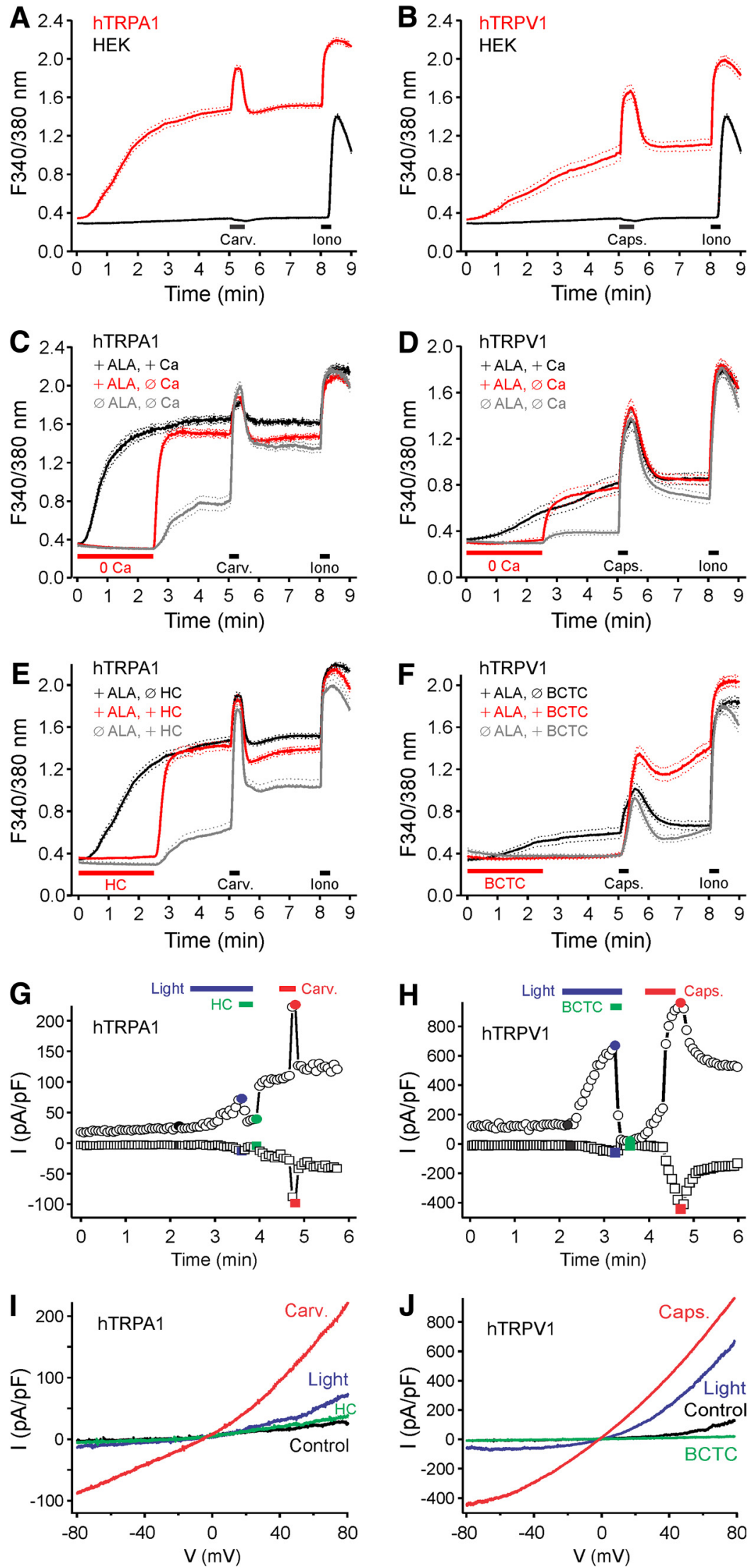

Figure 5. Pretreatment with ALA dramatically increases the photosensitivity of hTRPA1 and hTRPV1. HEK293t cells expressing hTRPA1 $(\boldsymbol{A})$, hTRPV1 $(\boldsymbol{B})$, and untransfected control cells were preincubated with ALA (300 $\mu \mathrm{m})$ for $3 \mathrm{~h}$ in the dark at $37^{\circ} \mathrm{C}$. The $340 / 380 \mathrm{~nm}$ illumination (10 ms each, $1 \mathrm{~Hz}$ ) increased intracellular calcium in cells expressing hTRPA1 and hTRPV1 but not in control HEK293t cells. hTRPA1 (C) and hTRPV1 (D) expressing cells preincubated with ALA (300 $\mu \mathrm{M}, 3 \mathrm{~h})$ were imaged in the in whole-cell currents in these cells (both $n=5$ for hTRPA1 and hTRPV1). However, blue light illumination in the presence of preapplied PpIX evoked large outwardly rectifying currents with a reversal potential close to $0 \mathrm{mV}$ both in hTRPA1-expressing cells $(n=6$; Fig. $8 A, B)$ and in hTRPV1-expressing cells $(n=5$; Fig. $8 C, D)$.

In C57BL/6 DRG neurons exposed to PpIX (100 nM, 4 min) the fura-2 illumination induced substantial calcium influx ( $n=278$ ). Compared with the WT, the PpIX-induced light response was only $15 \%$ in TRPA1 $1^{-/-}$neurons $(n=330, p<$ $0.001, t$ test independent samples), and $24 \%$ in TRPV1 $1^{-/-}$neurons $(n=209, p<$ 0.001 ; Fig. $8 E$ ). Illuminated PpIX activated $37 \%$ of the WT neurons (103 of 278 ), and $63 \%$ of these PpIX-sensitive neurons responded to carvacrol or capsaicin (65 neurons; Fig. 8F). Within all carvacrol- or capsaicin-sensitive neurons, $44 \%$ (65 of 148) responded to light under PpIX; the fraction of carvacrol- and capsaicin-insensitive neurons that were sensitized to light by PpIX was lower (29\%; 38 of $130, p<0.011, \chi^{2}$ test). Compared with $\mathrm{C} 57 \mathrm{BL} / 6$ DRG neurons, the fraction of PpIX light-sensitive cells was strongly reduced in TRPA $1^{-/-}$neurons to $6 \%$ (18 of 330 neurons, $p<0.001, \chi^{2}$ test), as well as in DRG neurons from TRPV1 ${ }^{-/-}$mice $(7 \%, 14$ of $209, p<$ $0.001)$. Finally, in TRPA $1^{-/-} / T R P V 1^{-/-}$ neurons, photosensitization by PpIX was almost completely abolished (1 of 266).

To ensure that the blue-light activation

$\leftarrow$

presence or absence of extracellular calcium. The calcium increase by the $340 / 380 \mathrm{~nm}$ illumination was abolished in calcium-free conditions, but large calcium transients occurred upon returning to a calcium-containing extracellular solution. Simply removing extracellular calcium in untreated hTRPA 1 or hTRPV1-expressing cells only produced small calcium transients upon returning to a calcium-containing extracellular solution. $\boldsymbol{E}, \boldsymbol{F}$, Cells were preincubated with ALA $(300 \mu \mathrm{m}, 3 \mathrm{~h})$ and imaged in the presence or absence of the TRPA1 antagonist HC-030031 (10 $\mu \mathrm{M}, \mathrm{HC}, \boldsymbol{E})$ and TRPV1 antagonist BCTC (1 $\mu \mathrm{M}, \boldsymbol{F})$. Calcium transients upon removal of $\mathrm{HC}-030031$ were larger in ALA-pretreated compared with untreated hTRPA1expressing cells. In contrast, washout of BCTC did not result in calcium transients in hTRPV1-expressing cells. Data are mean \pm SEM. G, Example of a whole-cell patch-clamp recording from an hTRPA1-expressing cell pretreated with ALA (300 $\mu \mathrm{M}, 3 \mathrm{~h})$. Stimulation by blue light $(460-490 \mathrm{~nm})$ induced a current that was inhibited by HC-030031 $(10 \mu \mathrm{M})$. $\boldsymbol{H}$, Example of a whole-cell patch-clamp recording from an hTRPV1expressing cell pretreated with ALA $(300 \mu \mathrm{m}, 3 \mathrm{~h})$. The current induced by stimulation with blue light was inhibited by BCTC $(1 \mu \mathrm{M}) . I, J$, Ramp currents recorded at the times indicated with corresponding color in $\mathbf{G}$ and $\boldsymbol{H}$. $\boldsymbol{A}-\boldsymbol{J}$, Carvacrol $100 \mu \mathrm{M}$ (Carv.); and capsaicin $300 \mathrm{~nm}$ (Caps.). 
of hTRPAl is mediated by excitation of PpIX producing an activator of the channel, most likely singlet oxygen, we used a cell-free model using purified full-length hTRPAl protein integrated into the artificial lipid bilayer for voltage-clamp recording of single-channel activity (Moparthi et al., 2014). The artificial membrane was illuminated by a $405 \mathrm{~nm}$ laser with a power density of $0.45 \mathrm{~mW} / \mathrm{mm}^{2}$, comparable with the monochromator illumination of HEK293t cells and DRG neurons described above. This stimulation evoked single-channel currents in the presence of PpIX $(1 \mu \mathrm{M})$ at positive and negative holding potential (Fig. 9A,B). The $\mathrm{P}_{\mathrm{o}}$ values were $0.30 \pm 0.03$ at $60 \mathrm{mV}$ $(n=7)$ and $0.41 \pm 0.08$ at $-60 \mathrm{mV}(n=$ 3). The $\mathrm{G}_{\mathrm{s}}$ values were $21 \pm 2 \mathrm{pS}$ at $60 \mathrm{mV}$ $(n=8)$ and $15 \pm 1 \mathrm{pS}$ at $-60 \mathrm{mV}(n=4)$. Without hTRPA1, no currents were elicited by the combination of $405 \mathrm{~nm}$ light and PpIX ( $n=4$; Fig. 9B). The unselective TRP channel pore blocker ruthenium red (40 $\mu \mathrm{M})$ abolished the hTRPAl activity $(n=3$; Fig. $9 C)$. In 2 of 4 separate experiments exposing hTRPA1 to only violet light, short initial (10 s) and minimal TRPA 1 activity at $60 \mathrm{mV}$ was observed $\left(P_{\mathrm{o}}\right.$ values were 0.04 and 0.07 ). TRPA 1 activity was negligible in the presence of PpIX alone $\left(P_{\mathrm{o}}\right.$ value was 0.02$)$ and only in 1 of 3 separate experiments at $60 \mathrm{mV}$. Thus, substantial hTRPA1 single-channel activity in this reductionistic model was only accomplished with violet light irradiation in the presence of PpIX.

\section{ALA and PpIX induce}

photosensitization of neuropeptide release through TRPA1 and TRPV1

Illumination of the C57BL/ 6 mouse hindpaw skin ex vivo with a cold (white) light source for $10 \mathrm{~min}$ did not induce an increase of CGRP release. Also, in the absence of light, PpIX $(5 \mu \mathrm{M})$ for $10 \mathrm{~min}$ caused no increase of CGRP release. However, in skin flaps preincubated with PpIX $(5 \mu \mathrm{M})$ in darkness for $30 \mathrm{~min}$, the same light stimulation caused a $36 \pm 4 \mathrm{pg} / \mathrm{ml}$ increase in CGRP release compared with the period before illumination $(p=0.001, n=$ 12, $t$ test dependent samples; Fig. 10A). This photosensitization by PpIX was substantially decreased in TRPA1 ${ }^{-/-}$and TRPV1 $1^{-/-}$mice (ANOVA, $F_{(3,38)}=6.2, p=0.002$ and $p=0.013$, HSD post hoc tests; Fig. 10B). Compared with the large difference between WT and TRPA1 ${ }^{-1-}$, less reduction of PpIX photosensitization was observed in the presence of the TRPA1 antagonist A-967079 (2 $\mu \mathrm{M})$ and in TRPV1 $1^{-/-} / T R P V 1^{-/-}$mice (both $n=9$ ).

In addition, the mouse trachea preparation was used because the sensory nerve endings come close to the very surface of the respiratory epithelium and because the preparation can be superfused with a thin layer of SIF not impeding light penetration. Exposure of the mouse trachea to $405 \mathrm{~nm}$ violet laser light $(0.45$ (Caps.).
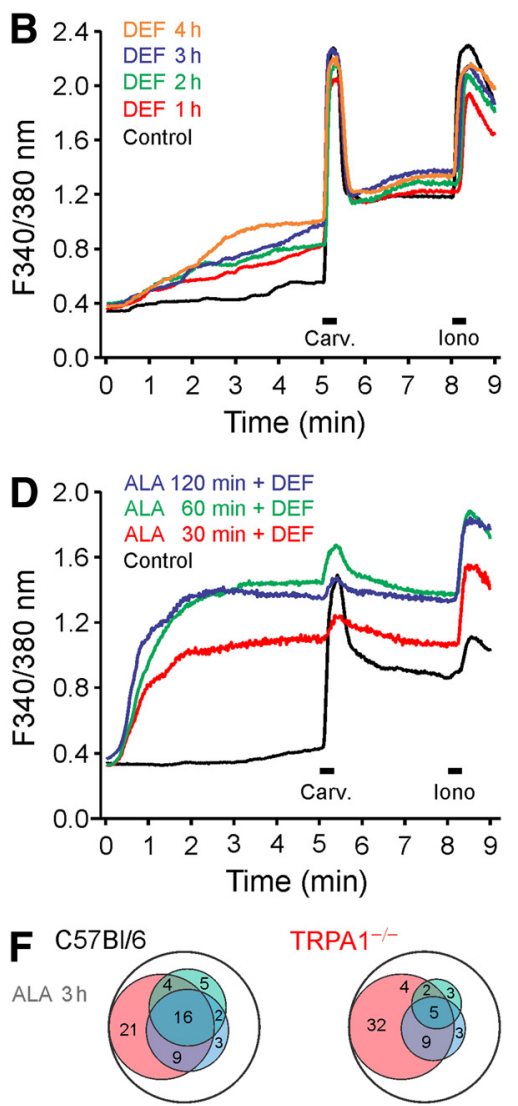

TRPV 1
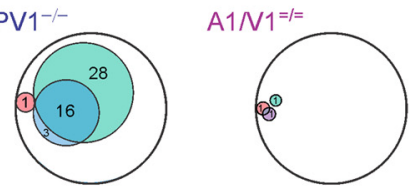

Light - sensitive Carvacrol-sensitive Capsaicin-sensitive

Figure 6. Modulation of photosensitivity by ALA and the activated population of sensory neurons. $A$, hTRPA1-expressing HEK293t cells were pretreated with the ALA-dehydratase inhibitor succinyl acetone ( $S A, 1 \mu \mathrm{m}, 4 \mathrm{~h}$ ), ALA (300 $\mu \mathrm{m}, 3 \mathrm{~h}$ ), or both (SA $4 \mathrm{~h}+\mathrm{ALA} 3 \mathrm{~h}$ ). Pretreatment with SA led to a diminished ALA-induced photosensitization of hTRPA1. B, hTRPA1-expressing cells $(n=399)$ were preincubated with ALA $(600 \mu \mathrm{M}, 3 \mathrm{~h})$. Bar chart represents the ratio increase by $340 / 380 \mathrm{~nm}$ illumination $(10 \mathrm{~ms}$ each; $1 \mathrm{~Hz}$ ). $\boldsymbol{F}$, Venn diagram of the neuronal populations activated by $340 / 380 \mathrm{~nm}$ light, carvacrol-sensitive neurons, and capsaicin-sensitive neurons. The number reflects the respective percentage of neurons. Encompassing circle represents the total neuronal population for each genotype. $\boldsymbol{A}-\boldsymbol{E}$, Data are mean \pm SEM. ${ }^{*} p<0.01 . \boldsymbol{A}-\boldsymbol{F}$, Carvacrol $50 \mu \mathrm{M}$ (Carv.); and capsaicin $1 \mu \mathrm{M}$

$\mathrm{mW} / \mathrm{mm}^{2}$ ) evoked a small but significant increase in CGRP release $(19 \pm 4 \mathrm{pg} / \mathrm{ml}, n=5$; Fig. $10 C)$, which continued rising during the first wash-out period. This constitutive light response in the SIF-preincubated trachea was almost abolished by the antagonist HC030031 $(50 \mu \mathrm{M})$ as well as in TRPA1 ${ }^{-/-}$animals, while it was unchanged in TRPV1 ${ }^{-1-}$ mice $(p=0.013$ and $p=$ 0.008 compared with control, $n=4-7$, HSD post hoc tests). The ubiquitous presence of PpIX in all cells might be sufficient to provide a genuine blue light sensitivity mediated by TRPA1, in agreement with our psychophysical finding that the same blue light caused pain in human skin.

After ALA $(100 \mu \mathrm{M}, 1 \mathrm{~h})$ preincubation, the $405 \mathrm{~nm}$ laser stimulation increased CGRP release sevenfold $(135 \pm 20 \mathrm{pg} / \mathrm{ml}$, $n=6$; Fig. 10D). Compared with their WT littermates, the 405 

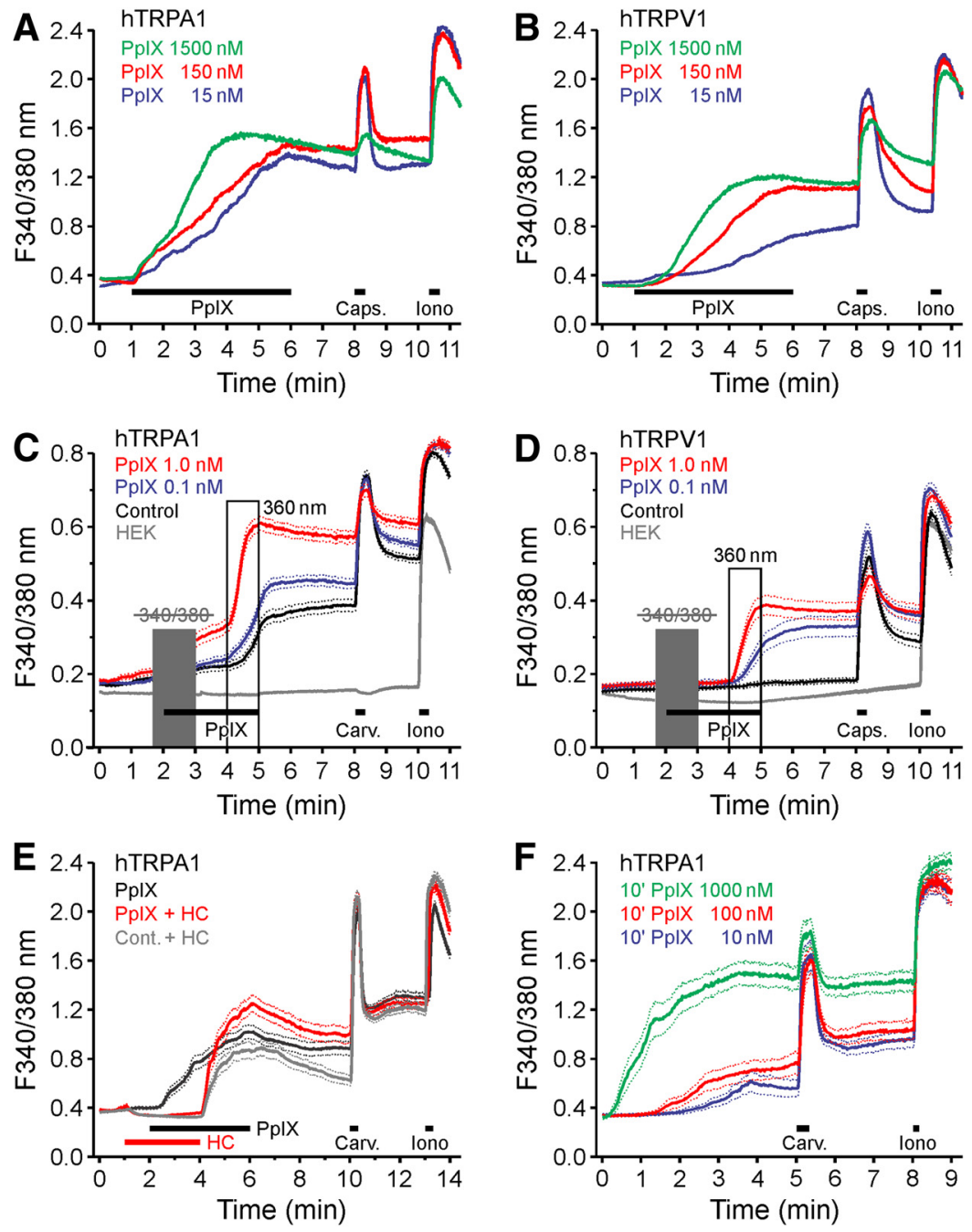

Figure 7. PpIX activates hTRPA1 and hTRPV1. $\boldsymbol{A}$, In hTRPA1-expressing HEK293t cells PpIX (PpIX, 5 min) evoked a concentration-dependent increase in $\left[\mathrm{Ca}^{2+}\right]_{\mathrm{i}}$. B, Similarly, hTRPV1-expressing cells challenged with PpIX showed concentrationdependent calcium increases. $C$, In hTRPA1-expressing cells, PpIX increased the UV response compared with untreated hTRPA1expressing cells or HEK293t cells. When the $340 / 380 \mathrm{~nm}$ illumination (10 ms each; $1 \mathrm{~Hz}$ ) within the first minute of PpIX application was omitted (gray box), a direct effect on intracellular calcium was observed for PpIX 1 nм, but not for PpIX 0.1 nм. D, hTRPV1expressing cells exposed to PpIX increased calcium upon illumination more than untreated hTRPV1-expressing cells or HEK293t cells. $\boldsymbol{E}$, hTRPA1-expressing cells were stimulated with PpIX $(20 \mathrm{~nm})$ in the absence or in the presence of TRPA1 antagonist HC-030031 (10 $\mu \mathrm{m}, \mathrm{HC}) . \boldsymbol{F}$, In hTRPA1-expressing cells preincubated for 10 min with PpIX and washed, the 340/380 nm illumination $\left(10 \mathrm{~ms}\right.$ each, $1 \mathrm{~Hz}$ ) caused a concentration-dependent increase in $\left[\mathrm{Ca}^{2+}\right]_{\mathrm{i}}$. Data are mean $\pm \mathrm{SEM}$.

nm-stimulated tracheal CGRP release after ALA pretreatment was only $17 \%$ in TRPA1 $1^{-/-}, 33 \%$ in $T R P V 1^{-/-}$, and $38 \%$ in TRPA $^{-1-} /$ TRPV1 $^{-/-}$(ANOVA, $F_{(3,15)}=12.3, p<0.001$, HSD post hoc tests; Fig. 10D). In the presence of both antagonists HC$030031(50 \mu \mathrm{M})$ and BCTC $(10 \mu \mathrm{M})$, the photosensitization by ALA was decreased to $37 \%$ (data not shown). Intriguingly, neither of the two TRP channel antagonists alone was able to significantly reduce the blue light response of the photosensitized trachea, only the combination was effective, while either of the two knock-out strains showed a marked reduction of the light sensitivity. The mere pharmacological inhibition of the one channel seems to be overcome by the activation of the other channel, as long as both proteins are present. If one of the channel proteins is missing, a putative synergism between the two TRP channels is lacking and light activation falls to the same low level as achieved by the combination of inhibitors.

\section{Discussion}

Porphyrias comprise a group of rare, but severe and highly disabling, diseases (Kauppinen, 2005). The cause of the disease is known: a nonfunctional enzyme in the ubiquitous heme biosynthetic pathway causes an accumulation, in particular in bone marrow and liver cells, of a biochemical intermediate, such as PpIX, which spills into the blood and extracellular fluids. This leads to either visceral pain symptoms (in acute porphyrias) or, in the case of porphyrin accumulation, cutaneous light hypersensitivity, the most disabling symptom of which is intense burning pain occurring within minutes of exposure to light, particularly in erythropoietic porphyria (Foran and Abel, 2003; Sassa, 2006; Horner et al., 2013; Tintle et al., 2014). The mechanism causing this pain was unexplained. In the most severely affected patients, the disease manifests during childhood, can be lifethreatening due to liver failure, and eventually necessitates blood transfusions and even bone marrow transplantation. Similarly, pain is the main adverse effect of PDT, which uses exogenous ALA or analogs to enhance production of PpIX in the target tissue, followed by prolonged illumination with visible red light (Halldin et al., 2011, 2013). However, all living cells contain and require PpIX as a part of the vitally important heme pathway. Thus, illumination of normal skin with the optimal wavelength $(405 \mathrm{~nm})$ to excite PpIX and generate singlet oxygen should also be able to evoke pain. This was the case in all of our human volunteers, and it occurred within 60 s. The double-blind study with subepidermal injections of ALA and vehicle revealed a dramatic augmentation of the blue light-induced pain due to photosensitization. Even then, the pain immediately subsided when the stimulating laser was switched off.

Our results identify the thermo-TRP channels TRPA1 and TRPV1 as key targets in the treatment of pain and inflammation evoked by light exposure in patients with cutaneous porphyrias or treated with PDT. Activation of TRPA1 by $\mathrm{UV}_{\mathrm{A}}$ light and the increased light sensitivity of the channel in presence of certain photosenzitizer molecules (hypericin and acridine orange) has been reported, as well as evidence for a role for ROS in mediating these effects (Hill and Schaefer, 2009). We found that constitutive TRPA1 photosensitivity occurs over a wide range of wavelengths, spanning both $\mathrm{UV}_{\mathrm{A}}$ and blue visible light, with highest efficiency in the range of $400-430 \mathrm{~nm}$. The increase in intracellular calcium concentration evoked in TRPA1-expressing HEK293t cells by illumination with $390 \mathrm{~nm}$ light is due to calcium entry, not release from intracellular stores, and is completely abolished in the presence of the TRPA1 antagonist HC-030031. Several cysteine residues from the cytoplasmic 

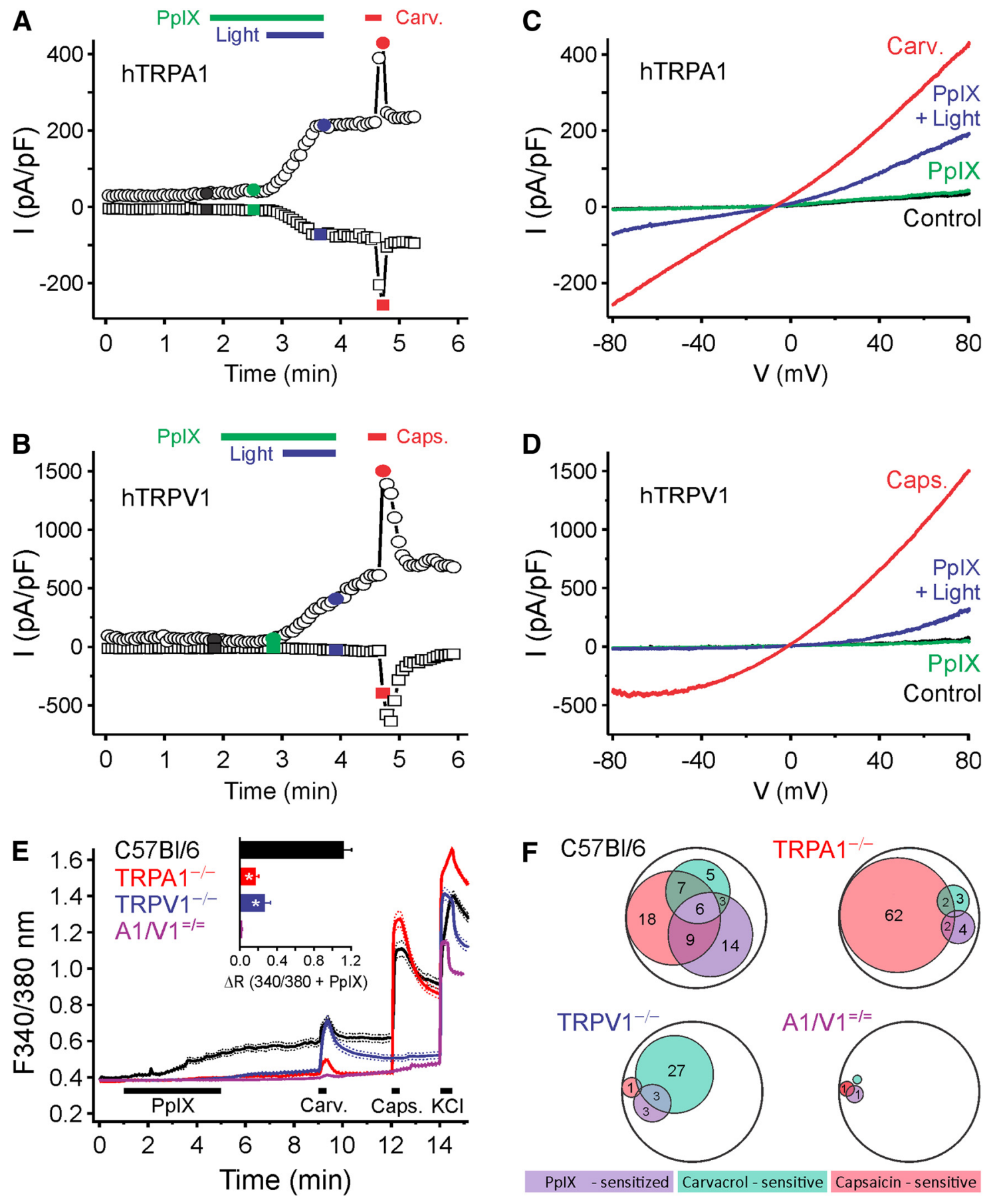

PplX - sensitized Carvacrol-sensitive Capsaicin-sensitive

Figure 8. Blue light ( $460-490 \mathrm{~nm})$ evokes $\mathrm{hTRPA1}$ - and hTRPV1-dependent membrane currents in the presence of PpIX. Example of a whole-cell patch-clamp recording from an (A) hTRPA1- or (B) hTRPV1-expressing HEK293t cell stimulated with PpIX (20 nm) and then blue light (60) in the presence of PplX, followed by carvacrol (100 $\mu \mathrm{M}$ ). Currents at $-80 \mathrm{mV}$ (squares) and $80 \mathrm{mV}$ (circles) of voltage ramps at regular intervals were recorded. $\boldsymbol{C}, \boldsymbol{D}$, Ramp currents recorded at the times indicated by the corresponding color in $\boldsymbol{A}$ and $\boldsymbol{B}$, respectively. $\boldsymbol{E}, \boldsymbol{F}$, PpIX activates a subpopulation of mouse DRG neurons; the effect is substantially reduced in DRGs from TRPA1 ${ }^{-1-}$ and TRPV1 ${ }^{-1-}$ mice and abolished in TRPA1 ${ }^{-1-} / T R P V 1^{-1-}$ mice. $E$, Compared with DRG neurons from WT ( $n=$ 278 cells) stimulated by PpIX (PpIX, $100 \mu \mathrm{m})$, the responses were substantially reduced in TRPA1 ${ }^{-/-}(n=330), \operatorname{TRPV}^{-/-}$neurons $(n=209)$, and $\operatorname{TRPA}^{-/-} / \operatorname{TRPV}^{-/-}(n=266)$. Data are mean \pm SEM. Inset, Comparison of the response amplitudes to PpIX during $340 / 380$ illumination. ${ }^{*} p<0.001$. F, Venn diagram of neuronal populations sensitive to PpIX, carvacrol, and capsaicin. The number reflects the respective percentage of neurons; the encompassing circle represents the total neuronal population. $\boldsymbol{A}-\boldsymbol{F}$, Carvacrol $50 \mu \mathrm{M}$ (Carv.); and capsaicin $1 \mu \mathrm{m}$ (Caps.).

$\mathrm{N}$ terminus domain of TRPA1 (C621, C641, C665, and particularly C633 and C651) appear to be critical for the light activation of the channel. Our previous work indicated the oxidative generation of N-terminal disulfide bonds between some of these cysteines; upon exposure to methylglyoxal, disulfide bonds between cysteines at positions 621/633 and positions 641/651 were observed (Eberhardt et al., 2012), while nitroxyl induced bonds between cysteines at positions 621/633 and positions 651/665 (Eberhardt et al., 2014). In both cases, the previously unsuspected amino acids 633 and 651 appear to be involved. Interestingly, sensitivity to light was abolished when cysteines 633 and 651 were replaced by serine, underlining the importance of these juxtamembrane cysteines for the sensitivity to electrophilic agonists and for oxidation of hTRPA1. The mechanism responsible for 

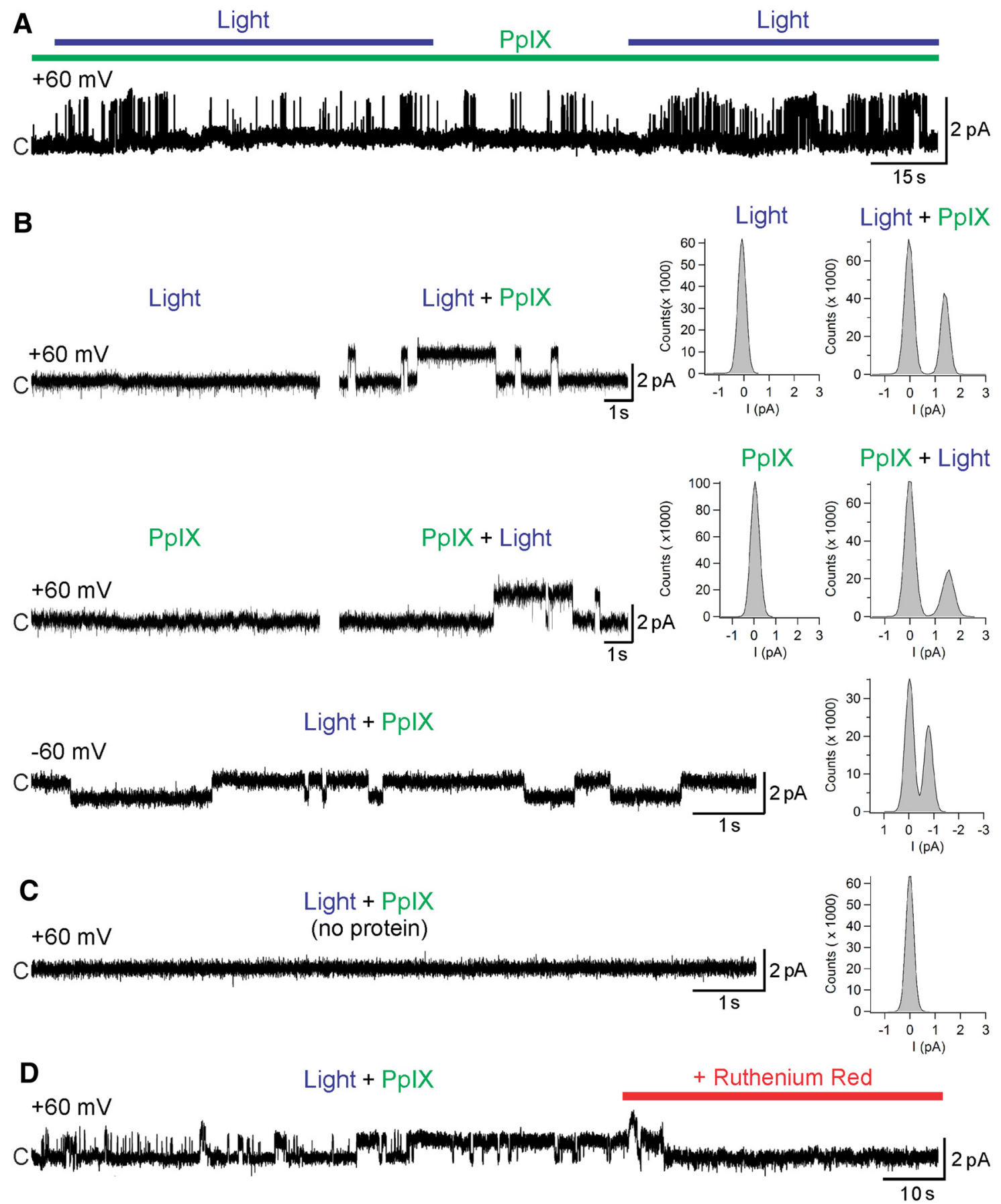

Figure 9. Purified hTRPA1 is activated by blue light in the presence of PpIX.A, Purified hTRPA1 was inserted into planar lipid bilayers. In the presence of protoporphyrin (PpIX) at $1 \mu \mathrm{M}$, exposure to $405 \mathrm{~nm}$ light triggered TRPA1 single-channel currents. $\boldsymbol{B}$, Neither light nor PpIX alone evoked channel activity, whereas their subsequent combination induced distinct single-channel openings at the steady-state test potentials of $60 \mathrm{mV}$ and $-60 \mathrm{mV}$. C, Bilayers without hTRPA1 did not respond to light in the presence of PpIX. D, The nonselective TRP channel blocker ruthenium red (40 $\mu \mathrm{m}$ ) abolished TRPA1 activity. Representative traces and the corresponding amplitude histograms are shown. c, Closed channel state.

hTRPV1 activation by oxidative agents also involves covalent modification of intracellular cysteines at positions 158, 387, 391, and 767 (Chuang and Lin, 2009).

Intracellular singlet oxygen generation by red light irradiation through Type II photosensitizing reactions appears to be the main effect responsible for biological actions during PDT, albeit superoxide anion radical may also be involved to some extent (Henderson and Dougherty, 1992). While exogenous photosensitizers can substantially enhance light-induced responses, native untreated (but not untransfected) cells also demonstrate consti- tutive photosensitivity, possibly due to intermediates of the ubiquitous heme pathway. Both hTRPA1-expressing cells and native mouse DRG neurons displayed calcium transients in response to illumination with $390 \mathrm{~nm}$ light. This activity is mediated via generation of ROS, as antioxidants NAC and DTT reduced the response to light stimulation. Moreover, the same stimulus that was used to evoke TRPA1-mediated calcium entry was sufficient to generate substantial responses from the fluorescent ROS indicators hydroethidine and $\mathrm{H}_{2} \mathrm{DCF}$. The precise identification and quantification of the actual ROS generated remain to be ad- 

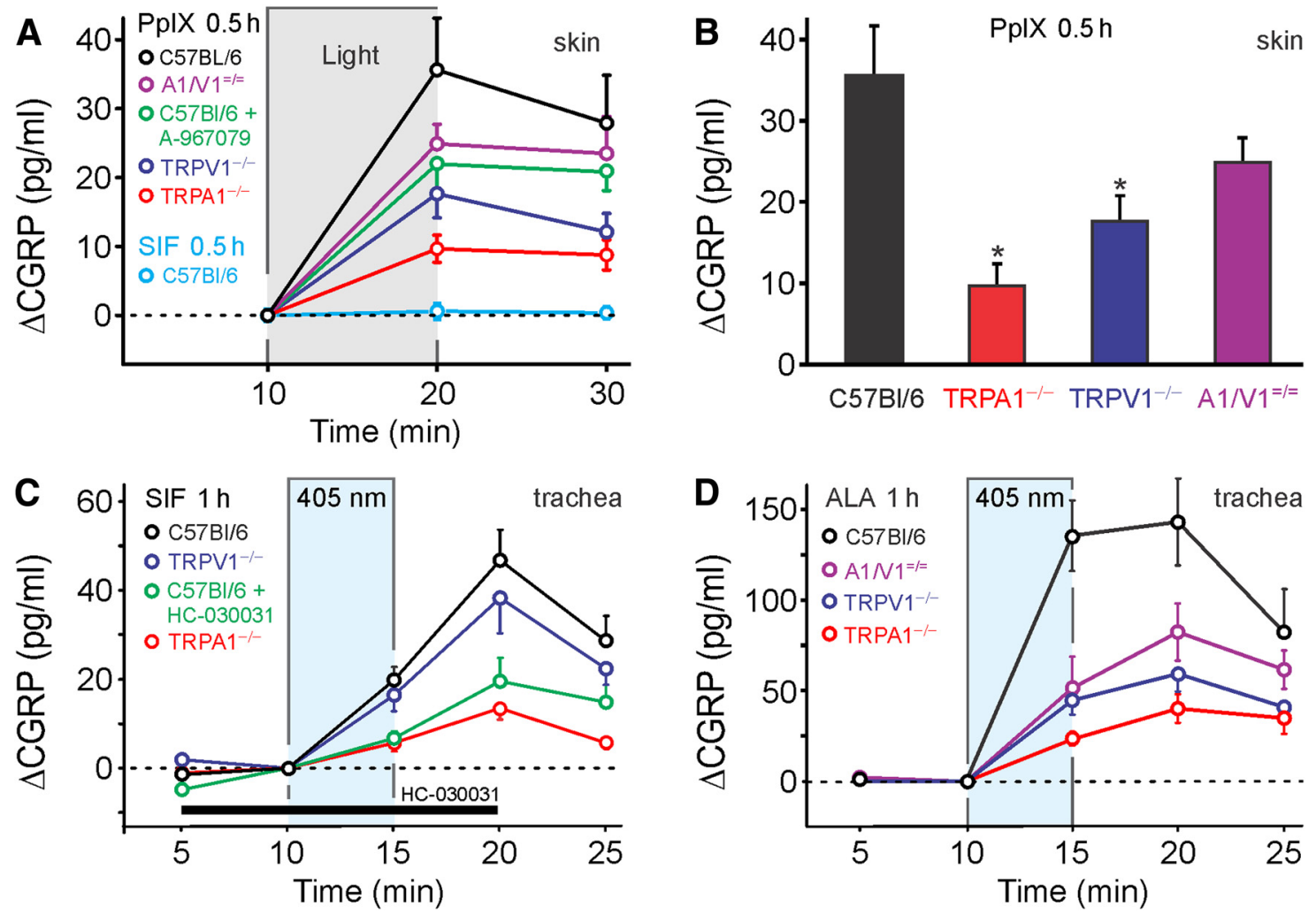

Figure 10. ALA and PpIX photosensitize neuropeptide release by activation of TRPA1 and TRPV1. $\boldsymbol{A}$, In isolated hindpaw skin, release of the neuropeptide CGRP was measured by EIA as index of neuronal activation. Compared with a period without illumination, an intense broad-spectrum light caused the release of CGRP from skin pretreated with PpIX (PpIX $5 \mu \mathrm{m}$ for 40 min, $n=10-12$ ). Compared with C57BL/6, CGRP release was substantially reduced in hindpaw skin of TRPA ${ }^{-/-}$and $T R P V 1^{-/-}$animals and absent without pretreatment by PpIX ( $n=8$ ). $B$, Comparison of the light-induced increase in CGRP release after PpIX pretreatment in the different genotypes ( $n=10-12, p<0.05$ vs $(57 B L / 6)$. C, The isolated superfused mouse trachea was stimulated by 405 nm laser illumination after $1 \mathrm{~h}$ in control solution (SIF). A slight but significant increase in CGRP release was observed in trachea from WT animals (C57BL/6, $n=7)$; this was reduced in TRPA1 ${ }^{-/-}$ animals $(n=4)$ and in the presence of HC-030031 $(n=4)$ but not in TRPV1 ${ }^{-/-}$animals $(n=4)$. D, After 1 h exposure to ALA $(100 \mu \mathrm{M})$, stimulation by the $405 \mathrm{~nm}$ laser caused a substantial increase in CGRP release. Compared with WT mice $(n=6)$, the light-induced CGRP release was significantly reduced in the trachea of $\operatorname{TRPA}^{-/-}(n=5), \operatorname{TRPV}^{-/-}(n=4)$, and $\operatorname{TRPA}^{-/-} / \operatorname{TRPV}^{-/-}$ $(n=4)$ animals. Data in the trachea are given as increase of CGRP ( $\Delta$ CGRP) over baseline.

dressed. While, for example, increased hydroethidine fluorescence is generally interpreted as being associated with superoxide formation, recent work has shown that most fluorescent ROS indicators available, including those used in this study, do not possess sufficient specificity to allow unequivocal ROS identification (Price and Kessel, 2010; Zielonka and Kalyanaraman, 2010). The fact that neither light per se nor the photosensitizer PpIX alone was able to evoke substantial hTRPA1 activity was emphasized with the purified channel protein reconstituted in artificial lipid bilayers, which showed single-channel activity as soon as PpIX was irradiated by the optimal wavelength (405 nm) to generate singlet oxygen (Rossi et al., 2008).

Using a heterologous expression system, we demonstrate that three procedures (application of ALA, PpIX, or inhibition of PpIX processing) leading to excess PpIX in human cells cause marked photosensitization mediated by two ion channels involved in pain signaling. Similarly, mouse DRG neurons in primary culture are rendered hypersensitive to light by preincubation with ALA as well as by acute application of PpIX. In both cases, photosensitivity is largely restricted to a subpopulation of carvacrol- and/or capsaicin-sensitive neurons, most likely nociceptors. Genetic ablation of TRPA1 and TRPV1 leads to a substantial reduction in the constitutive light sensitivity as well as in the hypersensitivity induced by ALA or PpIX. Interestingly, the fact that the PpIX-induced light sensitivity is reduced from $37 \%$ among WT neurons to the same extent by deletion of either
TRPA1 (to 6\%) or TRPV1 (to 7\%) suggests a synergy between the two channels, whereby activation of both TRPA1 and TRPV1 is required for a full-scale development of PpIX-enhanced photosensitivity. The same logical "or" relationship is evident from the trachea results: the photosensitized CGRP release is decreased to a similar degree in either TRPA1 or TRPV1 knock-outs, and the double knock-outs show no additive effect of the gene deletions. A similar interaction with supra-additive effects was recently reported for TRPA1 and TRPV1 expressed in rat vagal pulmonary C-fiber afferents (Lin et al., 2015). Several forms of indirect or direct interaction between both channels have been described and discussed (Fischer and Edwardson, 2014; Fischer et al., 2014). Although photosensitization induced by both ALA and PpIX was almost entirely abolished in DRG neurons from TRPA1 $1^{-/-} / \mathrm{TRPV1}^{-/-}$mice, we cannot rule out additional mechanisms contributing to this effect. ROS generated through PpIX-mediated photosensitization may activate other neuronal sensors of oxidative stress, such as TRPM2 (Nazıroğlu et al., 2011).

Our results obtained in cellular models were complemented by the investigation of intact nociceptive nerve endings ex vivo in mouse trachea and skin. The constitutive light sensitivity of mouse cultured sensory neurons was recapitulated in the particularly sensitive and translucent trachea preparation that even responds to visible, violet light in the absence of photosensitization and dependent on TRPA1 expression. Pretreatment with ALA or 
PpIX leads to photosensitization of these nerve endings in both trachea and skin from WT mice, as demonstrated by the increase in CGRP release during illumination. Light-induced CGRP release from tissues of TRPA $1^{-1-} / T R P V 1^{-/-}$mice was markedly diminished compared with the WT. The pharmacological inhibition of one TRP channel seems largely compensated by the activation of the other channel; each of the TRP channels alone was apparently able to provide the calcium influx required for the marked, but still submaximal, CGRP release. However, the complete deficiency of either one of the channel proteins was not compensated, as if both proteins together were required for full responsiveness. Consistently, the TRPA1 ${ }^{-/-} / T R P V 1^{-/-}$did not show a stronger, additive, reduction of the light response than the single knock-outs. This was in contrast to the complete abolition of photosensitization in DRG neurons from $T R P A 1^{-/-}$/ $T R P V 1^{-/-}$mice and may be explained by contributions from other cell types releasing nociceptor-activating agents in the intact tissue preparations. The described TRPA1-TRPV1 proteinprotein interaction (Fischer et al., 2014) may in part be explained by the recently discovered Tmem100, a small transmembrane protein that modulates the TRPA1-TRPV1-complex (Weng et al., 2015). Our results support the conclusion that TRPA1 and TRPV1 have an essential contribution to the pathologically enhanced activity of cutaneous nociceptors during PDT and in light-exposed porphyria patients.

The receptor channels TRPA1 and TRPV1 expressed in painsignaling nerve endings act as cellular sensors to detect the oxidative stress produced by near UV and visible blue light, which is enhanced in the presence of cellular or exogenous photosensitizers. Selective antagonists for these channels might provide pain relief in patients suffering from cutaneous porphyrias, as well as to increase the tolerance of PDT and thus the therapeutic efficiency of this procedure.

\section{References}

Ajioka RS, Phillips JD, Kushner JP (2006) Biosynthesis of heme in mammals. Biochim Biophys Acta 1763:723-736. CrossRef Medline

Andersson DA, Gentry C, Moss S, Bevan S (2008) Transient receptor potential Al is a sensory receptor for multiple products of oxidative stress. J Neurosci 28:2485-2494. CrossRef Medline

Averbeck B, Reeh PW (2001) Interactions of inflammatory mediators stimulating release of calcitonin gene-related peptide, substance $\mathrm{P}$ and prostaglandin E(2) from isolated rat skin. Neuropharmacology 40:416-423. CrossRef Medline

Balwani M, Desnick RJ (2012) The porphyrias: advances in diagnosis and treatment. Hematology Am Soc Hematol Am Soc Hematol Educ Program 2012:19-27. CrossRef Medline

Bretag AH (1969) Synthetic interstitial fluid for isolated mammalian tissue. Life Sci 8:319-329. CrossRef Medline

Caterina MJ, Schumacher MA, Tominaga M, Rosen TA, Levine JD, Julius D (1997) The capsaicin receptor: a heat-activated ion channel in the pain pathway. Nature 389:816-824. CrossRef Medline

Chuang HH, Lin S (2009) Oxidative challenges sensitize the capsaicin receptor by covalent cysteine modification. Proc Natl Acad Sci U S A 106: 20097-20102. CrossRef Medline

Dittert I, Benedikt J, Vyklický L, Zimmermann K, Reeh PW, Vlachová V (2006) Improved superfusion technique for rapid cooling or heating of cultured cells under patch-clamp conditions. J Neurosci Methods 151: 178-185. CrossRef Medline

Eberhardt MJ, Filipovic MR, Leffler A, de la Roche J, Kistner K, Fischer MJ, Fleming T, Zimmermann K, Ivanovic-Burmazovic I, Nawroth PP, Bierhaus A, Reeh PW, Sauer SK (2012) Methylglyoxal activates nociceptors through transient receptor potential channel A1 (TRPA1): a possible mechanism of metabolic neuropathies. J Biol Chem 287:28291-28306. CrossRef Medline

Eberhardt M, Dux M, Namer B, Miljkovic J, Cordasic N, Will C, Kichko TI, de la Roche J, Fischer M, Suárez SA, Bikiel D, Dorsch K, Leffler A, Babes A,
Lampert A, Lennerz JK, Jacobi J, Martí MA, Doctorovich F, Högestätt ED, et al. (2014) H2S and NO cooperatively regulate vascular tone by activating a neuroendocrine HNO-TRPA1-CGRP signalling pathway. Nat Commun 5:4381. CrossRef Medline

Fink C, Enk A, Gholam P (2015) Photodynamic therapy: aspects of pain management. J Dtsch Dermatol Ges 13:15-22. CrossRef Medline

Fischer MJ, Edwardson JM (2014) Validating TRP channel heteromers. Temperature 1:26-27. CrossRef

Fischer MJ, Balasuriya D, Jeggle P, Goetze TA, McNaughton PA, Reeh PW, Edwardson JM (2014) Direct evidence for functional TRPV1/TRPA1 heteromers. Pflugers Arch 466:2229-2241. CrossRef Medline

Foran SE, Abel G (2003) Guide to porphyrias: a historical and clinical perspective. Am J Clin Pathol 119 [Suppl]:S86-S93.

Fukuhara H, Inoue K, Kurabayashi A, Furihata M, Fujita H, Utsumi K, Sasaki J, Shuin T (2013) The inhibition of ferrochelatase enhances 5 -aminolevulinic acid-based photodynamic action for prostate cancer. Photodiagnosis Photodyn Ther 10:399-409. CrossRef Medline

Gholam P, Denk K, Sehr T, Enk A, Hartmann M (2010) Factors influencing pain intensity during topical photodynamic therapy of complete cosmetic units for actinic keratoses. J Am Acad Dermatol 63:213-218. CrossRef Medline

Gibson SL, Havens JJ, Metz L, Hilf R (2001) Is delta-aminolevulinic acid dehydratase rate limiting in heme biosynthesis following exposure of cells to delta-aminolevulinic acid? Photochem Photobiol 73:312-317. CrossRef Medline

Halldin CB, Gillstedt M, Paoli J, Wennberg AM, Gonzalez H (2011) Predictors of pain associated with photodynamic therapy: a retrospective study of 658 treatments. Acta Derm Venereol 91:545-551. CrossRef Medline

Halldin CB, Gonzalez H, Wennberg AM, Lepp M (2013) Patients' experiences of pain and pain relief during photodynamic therapy on actinic keratoses: an interview study. Acta Derm Venereol 93:433-437. CrossRef Medline

Henderson BW, Dougherty TJ (1992) How does photodynamic therapy work? Photochem Photobiol 55:145-157. CrossRef Medline

Herrick AL, McColl KE (2005) Acute intermittent porphyria. Best Pract Res Clin Gastroenterol 19:235-249. CrossRef Medline

Hill K, Schaefer M (2009) Ultraviolet light and photosensitising agents activate TRPA1 via generation of oxidative stress. Cell Calcium 45:155-164. CrossRef Medline

Horner ME, Alikhan A, Tintle S, Tortorelli S, Davis DM, Hand JL (2013) Cutaneous porphyrias: I. Epidemiology, pathogenesis, presentation, diagnosis, and histopathology. Int J Dermatol 52:1464-1480. CrossRef Medline

Ishizuka M, Abe F, Sano Y, Takahashi K, Inoue K, Nakajima M, Kohda T, Komatsu N, Ogura S, Tanaka T (2011) Novel development of 5-aminolevurinic acid (ALA) in cancer diagnoses and therapy. Int Immunopharmacol 11:358-365. CrossRef Medline

Kauppinen R (2005) Porphyrias. Lancet 365:241-252. CrossRef Medline

Kichko TI, Niedermirtl F, Leffler A, Reeh PW (2015) Irritant volatile anesthetics induce neurogenic inflammation through TRPA1 and TRPV1 channels in the isolated mouse trachea. Anesth Analg 120:467-471. CrossRef Medline

Kress M, Petersen M, Reeh PW (1997) Methylene blue induces ongoing activity in rat cutaneous primary afferents and depolarization of DRG neurons via a photosensitive mechanism. Naunyn Schmiedebergs Arch Pharmacol 356:619-625. CrossRef Medline

Lecha M, Puy H, Deybach JC (2009) Erythropoietic protoporphyria. Orphanet J Rare Dis 4:19. CrossRef Medline

Lin YJ, Lin RL, Ruan T, Khosravi M, Lee LY (2015) A synergistic effect of simultaneous TRPA1 and TRPV1 activations on vagal pulmonary C-fiber afferents. J Appl Physiol 1985 118:273-281. CrossRef Medline

Macpherson LJ, Dubin AE, Evans MJ, Marr F, Schultz PG, Cravatt BF, Patapoutian A (2007) Noxious compounds activate TRPAl ion channels through covalent modification of cysteines. Nature 445:541-545. CrossRef Medline

Moparthi L, Survery S, Kreir M, Simonsen C, Kjellbom P, Högestätt ED, Johanson U, Zygmunt PM (2014) Human TRPA1 is intrinsically coldand chemosensitive with and without its $\mathrm{N}$-terminal ankyrin repeat domain. Proc Natl Acad Sci U S A 111:16901-16906. CrossRef Medline

Muguruma N, Okamoto K, Kimura T, Kishi K, Okahisa T, Okamura S, Takayama T (2012) Endoscopic ablation therapy for gastrointestinal superficial neoplasia. Dig Endosc 24:139-149. CrossRef Medline 
Nazıroğlu M, Özgül C, Çiğ B, Doğan S, Uğuz AC (2011) Glutathione modulates $\mathrm{Ca}(2+)$ influx and oxidative toxicity through TRPM2 channel in rat dorsal root ganglion neurons. J Membr Biol 242:109-118. CrossRef Medline

Nowak-Sliwinska P, van den Bergh H, Sickenberg M, Koh AH (2013) Photodynamic therapy for polypoidal choroidal vasculopathy. Prog Retin Eye Res 37:182-199. CrossRef Medline

Poblete-Gutiérrez P, Wiederholt T, Merk HF, Frank J (2006) The porphyrias: clinical presentation, diagnosis and treatment. Eur J Dermatol 16: 230-240. Medline

Price M, Kessel D (2010) On the use of fluorescence probes for detecting reactive oxygen and nitrogen species associated with photodynamic therapy. J Biomed Opt 15:051605. CrossRef Medline

Puy H, Gouya L, Deybach JC (2010) Porphyrias. Lancet 375:924-937. CrossRef Medline

Rossi LM, Silva PR, Vono LL, Fernandes AU, Tada DB, Baptista MS (2008) Protoporphyrin IX nanoparticle carrier: preparation, optical properties, and singlet oxygen generation. Langmuir 24:12534-12538. CrossRef Medline

Sassa S (2006) Modern diagnosis and management of the porphyrias. Br J Haematol 135:281-292. CrossRef Medline

Snyder JW, Skovsen E, Lambert JD, Ogilby PR (2005) Subcellular, timeresolved studies of singlet oxygen in single cells. J Am Chem Soc 127: 14558-14559. CrossRef Medline

Story GM, Peier AM, Reeve AJ, Eid SR, Mosbacher J, Hricik TR, Earley TJ,
Hergarden AC, Andersson DA, Hwang SW, McIntyre P, Jegla T, Bevan S, Patapoutian A (2003) ANKTM1, a TRP-like channel expressed in nociceptive neurons, is activated by cold temperatures. Cell 112:819-829. CrossRef Medline

Tintle S, Alikhan A, Horner ME, Hand JL, Davis DM (2014) Cutaneous porphyrias: II. Treatment strategies. Int J Dermatol 53:3-24. CrossRef Medline

Wang L, Sterling B, Don P (2002) Berloque dermatitis induced by "Florida water." Cutis 70:29-30. Medline

Warren CB, Karai LJ, Vidimos A, Maytin EV (2009) Pain associated with aminolevulinic acid-photodynamic therapy of skin disease. J Am Acad Dermatol 61:1033-1043. CrossRef Medline

Weng HJ, Patel KN, Jeske NA, Bierbower SM, Zou W, Tiwari V, Zheng Q, Tang Z, Mo GC, Wang Y, Geng Y, Zhang J, Guan Y, Akopian AN, Dong X (2015) Tmem100 is a regulator of TRPA1-TRPV1 complex and contributes to persistent pain. Neuron 85:833-846. CrossRef Medline

Wondrak GT, Jacobson MK, Jacobson EL (2006) Endogenous UVAphotosensitizers: mediators of skin photodamage and novel targets for skin photoprotection. Photochem Photobiol Sci 5:215-237. CrossRef Medline

Zielonka J, Kalyanaraman B (2010) Hydroethidine- and MitoSOX-derived red fluorescence is not a reliable indicator of intracellular superoxide formation: another inconvenient truth. Free Radic Biol Med 48:9831001. CrossRef Medline 